\title{
Transcription Factors Associated with Abiotic and Biotic Stress Tolerance and Their Potential for Crops Improvement
}

\author{
Elamin Hafiz Baillo ${ }^{1,2,3,4}$, Roy Njoroge Kimotho ${ }^{1,2}$, Zhengbin Zhang ${ }^{1,2,3, *}$ and Ping Xu ${ }^{1,2,3}$ \\ 1 Key Laboratory of Agricultural Water Resources, Hebei Laboratory of Agricultural Water Saving, \\ Center for Agricultural Resources Research, Institute of Genetics and Developmental Biology, \\ University of Chinese Academy of Sciences, Shijiazhuang, Hebei 050021, China; \\ aminomooon14@gmail.com (E.H.B.); kimroybiotech@gmail.com (R.N.K.); xuping@sjziam.ac.cn (P.X.) \\ 2 University of Chinese Academy of Sciences, Beijing 100049, China \\ 3 Innovation Academy for Seed Design, Chinese Academy of Sciences, Beijing 100101, China \\ 4 Agricultural Research Corporation (ARC), Ministry of Agriculture, Gezira 21111, Sudan \\ * Correspondence: zzb@sjziam.ac.cn
}

Received: 4 August 2019; Accepted: 17 September 2019; Published: 30 September 2019

\begin{abstract}
In field conditions, crops are adversely affected by a wide range of abiotic stresses including drought, cold, salt, and heat, as well as biotic stresses including pests and pathogens. These stresses can have a marked effect on crop yield. The present and future effects of climate change necessitate the improvement of crop stress tolerance. Plants have evolved sophisticated stress response strategies, and genes that encode transcription factors (TFs) that are master regulators of stress-responsive genes are excellent candidates for crop improvement. Related examples in recent studies include TF gene modulation and overexpression approaches in crop species to enhance stress tolerance. However, much remains to be discovered about the diverse plant TFs. Of the $>80 \mathrm{TF}$ families, only a few, such as NAC, MYB, WRKY, bZIP, and ERF/DREB, with vital roles in abiotic and biotic stress responses have been intensively studied. Moreover, although significant progress has been made in deciphering the roles of TFs in important cereal crops, fewer TF genes have been elucidated in sorghum. As a model drought-tolerant crop, sorghum research warrants further focus. This review summarizes recent progress on major TF families associated with abiotic and biotic stress tolerance and their potential for crop improvement, particularly in sorghum. Other TF families and non-coding RNAs that regulate gene expression are discussed briefly. Despite the emphasis on sorghum, numerous examples from wheat, rice, maize, and barley are included. Collectively, the aim of this review is to illustrate the potential application of TF genes for stress tolerance improvement and the engineering of resistant crops, with an emphasis on sorghum.
\end{abstract}

Keywords: transcription factors; abiotic and biotic stress response; overexpression; gene; sorghum

\section{Introduction}

Abiotic and biotic stresses are major environmental threats that greatly reduce crop yield. Examples of abiotic stresses include drought, salt, cold, and heat, and biotic stresses include diverse living organisms, such as fungi, bacteria, viruses, nematodes, and insects [1,2]. Plants live continually with these stresses, giving rise to complex response interactions, but nevertheless crop productivity is severely impacted. For instance, abiotic stresses can reportedly cause yield losses of more than $50 \%$ [3], and the yield loss due to biotic stresses has been estimated as $35 \%$ [4]. Considering future climate change scenarios and harsh weather conditions, there is an urgent need to better understand the 
complex responses of plants to single and combined stresses, to ultimately enhance crop tolerance to changing climate conditions.

Cereals include more than 10,000 species worldwide, and the following five cereal crops provide much of the world's food [5]: wheat (Triticum sp.), rice (Oryza sativa), maize (Zea mays), barley (Hordeum vulgare), and sorghum (Sorghum bicolor). Among cereals, sorghum is the fifth most important crop and has unique adaptations that allow it to withstand harsh conditions at different growth stages [6,7]. Sorghum is a $\mathrm{C} 4$ species with a small genome size $(730 \mathrm{Mb})$, making it an ideal model for genomic and functional studies of plant growth under stress conditions [8]. Because it thrives under water scarcity and high temperatures, it is also an excellent model species for transcription factor studies aimed at enhancing tolerance or resistance to stresses, particularly drought [9]. Plant response strategies to abiotic and biotic stresses involve changes at the molecular, cellular, biochemical, and physiological levels. These various responses are generally controlled by several key genes encoding transcription activators and repressors that regulate downstream stress-induced genes and pathways. In the last decade, extensive research has helped identify key factors involved in abiotic and biotic stress responses [10].

Transcription factors (TFs) are central regulators of gene expression, and as such they modulate essential aspects of plant function, including responses to environmental factors and hormones, and cell differentiation and organ development [11]. TFs modulate gene expression by binding to local and distal cis-elements of a given gene under different biological contexts. Inukai et al. [12] highlighted recent findings that elaborate how TF interactions, local DNA structure, and genomic features can influence TF binding to DNA. Central to the function of TFs is their ability to bind specific DNA sequences and interact with different proteins in transcriptional complexes that regulate the expression of a vast number of genes. Accordingly, deciphering the mechanistic actions of TFs is essential for future studies. In plants, $10 \%$ of genes encode TFs [13], which take part at different stages for a specific function. Several TF databases are now available and provide comprehensive information about TF families in different species (Table 1). In plant transcription factor database (plant TFDB v5.0, Center for Bioinformatics, Peking University), 134 WRKY, 180 NAC, 145 MYB, 172 ERF, and 166 bZIP genes have been identified in sorghum (Figure 1). TFs are promising candidates for genetic engineering due to their roles as master regulators of several stress-related genes. Many TF families, including WRKY, MYB, NAC, and bZIP (Table 2), have been implicated in stress responses, and many TF genes are associated with enhanced tolerance in both model and crop plants [14]. In Arabidopsis, $\sim 30 \mathrm{TF}$ families are predicted to include $1922 \mathrm{TFs}$ involved in different functions [8]. A total of $2448 \mathrm{TFs}$ has been reported in sorghum, along with 1611 in rice and 3337 in maize [15]. In the last two decades, a wealth of studies have identified TF genes and characterized their responses to abiotic and biotic stresses. The improvement of plant stress tolerance by manipulating the expression of TF genes has become a hot area of research, as many of these genes are stress-responsive and govern a plethora of downstream genes. Accordingly, there is potential to engineer crops with higher stress tolerance [16]. In this context, considerable progress has been made through the overexpression of several TF genes.

This review summarizes recent studies on the major TF families involved in abiotic and biotic stress responses and their potential to boost stress tolerance in sorghum. Recent studies of TFs in major cereal crops (wheat, rice, maize, and barley) are discussed; also, TFs involved in stress responses in sorghum are highlighted. Other recent reviews about stress response TFs in other crops include one by Kimotho et al. [17], which covers maize TFs involved in abiotic stress, and another by Hong et al. [18], which provides a comprehensive update on wheat TFs involved in defense responses against pathogen infection. 
Table 1. Plant transcription factor databases.

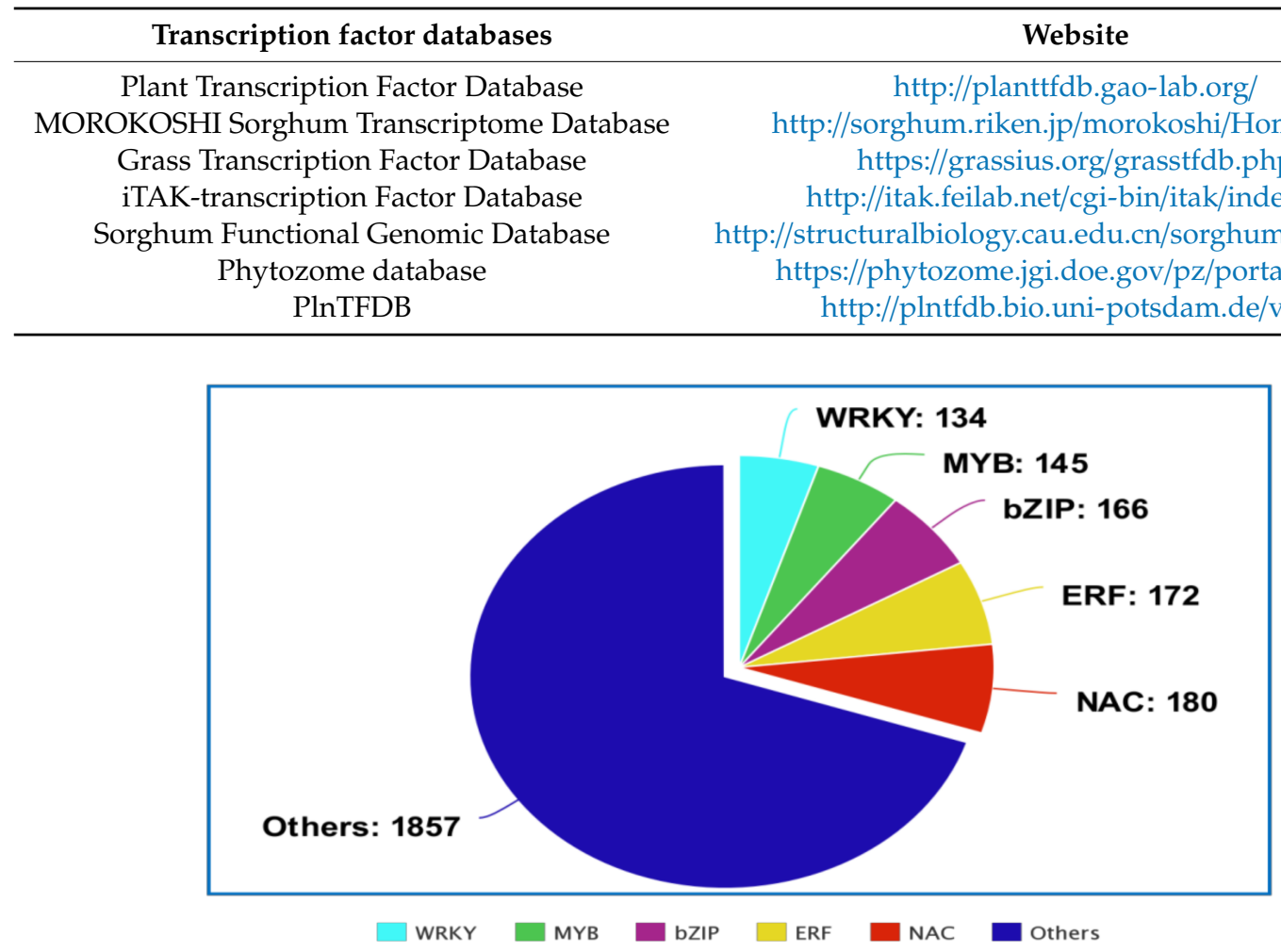

Figure 1. Pie chart showing the number of transcription factor (TF) genes in NAC, MYB, ERF, bZIP, WRKY, and other families in sorghum.

Table 2. General features of the discussed transcription factor (TF) families.

\begin{tabular}{|c|c|c|c|}
\hline TF Family & DNA-binding Domain & Cis-acting Element & Structural Features \\
\hline NAC & NAC domain & NACRS (TCNACACGCATGT) & $\begin{array}{l}\text { NAC domain consist of } 150 \text { amino } \\
\text { acids residues in N-terminal and } \\
\text { variable transcription regulatory in } \\
\text { their C-terminal. }\end{array}$ \\
\hline МYB & MYB domain & MYBR (TAACNA/G) & $\begin{array}{l}\text { MYB domain composed of multiple } \\
\text { repeats each repeat about } 52 \text { amino } \\
\text { acids which forming a } \\
\text { helix-turn-helix (HTH) structure. }\end{array}$ \\
\hline WRKY & WRKYGQK domain & W-box (TTGACT/C) & $\begin{array}{l}\text { WRKY domain is } \sim 60 \text { amino acid } \\
\text { residues in length, and also has a } \\
\text { zinc-finger structure at the } \mathrm{C} \text {-terminus } \\
\text { which either } \mathrm{Cx}_{4-5} \mathrm{Cx}_{22-23} \mathrm{HxH} \text { or } \\
\qquad \mathrm{Cx}_{7} \mathrm{Cx}_{23} \mathrm{HxC} \text {. }\end{array}$ \\
\hline ERF/DREB & AP2/ERF domain & $\begin{array}{l}\text { GCC box (AGCCGCC) and } \\
\text { (TACCGACAT) }\end{array}$ & $\begin{array}{l}\text { Composed of } 60 \text { amino acids with } \\
\text { conserved domain consist of Three } \\
\text { parallel } \beta \text {-sheets and putative } \\
\text { amphiphilic } \alpha \text {-helix. }\end{array}$ \\
\hline bZIP & bZIP domain & $\begin{array}{c}\text { C-box (GACGTC), A-box } \\
\text { (TACGTA), G-box (CACGTG), } \\
\text { PB-like (TGAAAA), and GLM } \\
\text { (GTGAGTCAT) }\end{array}$ & $\begin{array}{l}\text { bZIP domain consist of } \sim 16 \text { amino } \\
\text { acid residues which containing } \\
\text { nuclear localization signal followed } \\
\text { by an invariant } N-x 7-R / K \text { motif } \\
\text { contacts the DNA. }\end{array}$ \\
\hline
\end{tabular}

\section{The Regulatory Functions of Plant TFs in Response to Abiotic and Biotic Stresses}

Plants have evolved rapid response strategies to unfavorable conditions, and these involve interconnected networks at the molecular level controlled by signal cascades. The different components 
of stress responses are signal perception, signal transduction, and expression of stress-responsive genes [19]. When plant cells perceive a stress signal, receptors or sensors in the cell wall or membrane detect the stress stimulus, followed by a rapid response that transduces the external signal to intracellular signals. Signal cascades involving intracellular molecules or ions are activated along with kinase cascades, which are generally cytoplasmic. Major cascades are associated with reactive oxygen species (ROS) and calcium ions $\left(\mathrm{Ca}^{2+}\right)$. Phytohormones, including abscisic acid (ABA), jasmonic acid (JA), salicylic acid (SA), and ethylene (ET), are powerful second messengers that coordinate signal transduction pathways during stress responses. These signals activate several parallel transduction pathways, which often involve phosphatases and protein kinases [19]. Following the initial step of signal perception, plants activate two major signal cascades: the mitogen-activated protein kinase (MAPK) and calcium-dependent protein kinase (CDPK) pathways $[10,20]$. Finally, specific TFs are upregulated or downregulated by protein kinases or phosphatases, and the TFs bind to cis-elements of stress-related genes to enhance or suppress their transcription. Figure 2 broadly summarizes the general activation and activity of TFs. Because many interactions establish the regulatory networks that modulate the expression of stress-responsive genes, the functions of TFs in plants are tremendous in scope. Fundamentally, however, TFs modulate the expression of key downstream genes. The following sections summarize recent findings on the major TF families.

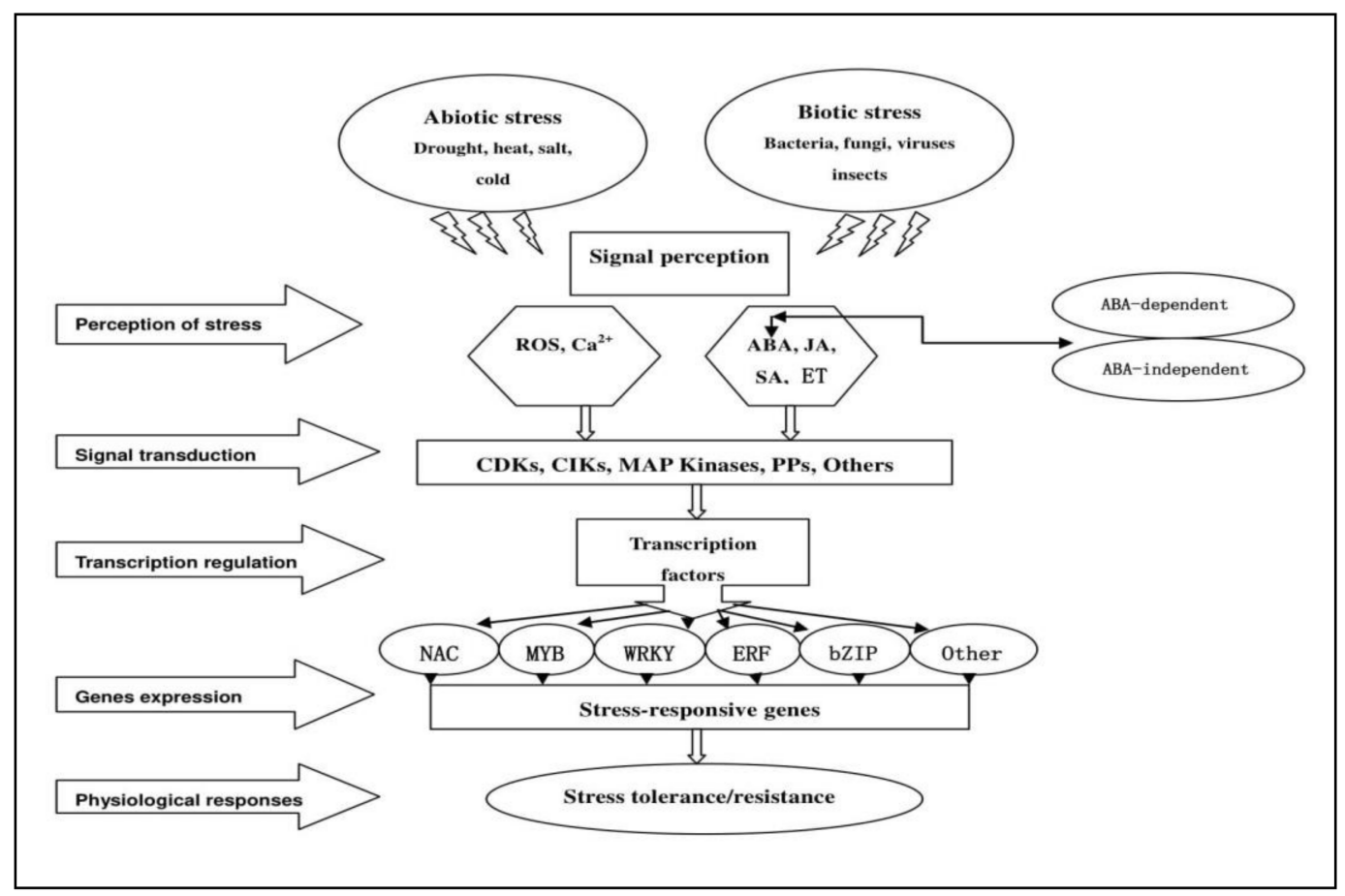

Figure 2. A schematic model of the signaling pathways involved in abiotic and biotic stress responses.

\section{NAC TFs}

The NAC (NAM, CUC, and ATAF) TF family is one of the largest plant-specific TF families [21]. The first reported NAC proteins include NAM from petunia (Petunia hybrida) [22] and Arabidopsis thaliana Ataf1/2 and Cuc2 proteins [23]. NAC TFs are characterized by a highly conserved DNA-binding NAC domain ( 150 amino acids) in the $\mathrm{N}$-terminal region. In contrast, their C-terminal transcription regulatory (TR) domains are diverse. These NAC protein TR domains contain a transmembrane domain that can either activate or repress transcription [24]. Previous studies have shown that NAC proteins act via an ABA-dependent pathway as well as an ABA-independent pathway, and play a vital role in both abiotic and biotic stresses [25]. Genome-wide studies and expression analyses have identified $N A C$ genes in different species; for example, there are 117 nonredundant $N A C$ genes in Arabidopsis and 151 in rice [26], and 87 NAC genes were recently reported in sesame [27]. Functional studies have 
shown that NAC genes can be induced by different abiotic stresses, such as the induction of Arabidopsis ANAC055 expression by drought, ANAC072 by ABA, and ANAC019 by salinity. Overexpression of these three genes in Arabidopsis resulted in improved drought tolerance [28,29]. NAC genes have also been found to regulate defense responses to pathogen invasion, wounding, and insect feeding [24].

Genome-wide analysis in sorghum identified 145 NAC genes, including those potentially involved in abiotic stress responses. Seven stress-related NAC genes (SbNAC6, SbNAC17, SbNAC26, SbNAC46, $S b N A C 56, S b N A C 58$, and $S b N A C 73$ ) had varying expression levels over time in response to various stresses (salinity, cold, ABA, and dehydration), indicating the potential functions of SbNAC genes under abiotic stress conditions [30]. A separate systematic analysis of the sorghum genome [31] identified 131 SbNAC genes encoding 183 proteins. The authors characterized 13 SbNAC genes as responsive to abiotic stress. qRT-PCR expression profiling of two cultivars, one tolerant and one susceptible, showed that eight SbNAC genes acted as positive (SbNAC014, SbNAC034, SbNAC035, $S b N A C 037$, and SbNAC041) or negative (SbNAC052, SbNAC073, and SbNAC116) regulators in response to post-flowering drought stress in sorghum. Moreover, under this stress condition, the expression levels of some $S b N A C$ genes were significantly related to grain yield, indicating their involvement in yield maintenance and drought tolerance [30]. The abiotic stress response gene SbSNAC1 is reportedly induced by drought, salinity, and ABA, with SbSNAC1 overexpression leading to enhanced drought stress tolerance in transgenic Arabidopsis plants. Interestingly, the transactivation activity of $S b N A C 1$ is associated with its $\mathrm{C}$-terminal region rather than $\mathrm{N}$-terminus NAC domain [32]. SbSNAC1 is closely related to maize $Z m S N A C 1$ and rice $S N A C 1$, and all three genes have been shown to play a crucial role in abiotic stress responses [33].

Recent studies have shown that NAC TFs are also involved in biotic stress responses. For example, Zhang and Huang. [34] reported the induction of NAC TFs in response to greenbug infestation in sorghum. RNA-sequencing analysis indicated that many NAC genes were expressed in response to greenbug attack. The authors concluded that $S b N A C$ genes have diverse functions in response to greenbug infestation and may therefore contribute to genetic resistance to greenbug.

In wheat, Zhang et al. [35] reported that the TaNAC47 gene is induced by cold, salt, drought, and ABA, based on differential expression levels. TaNAC47 overexpression in transgenic Arabidopsis led to ABA hypersensitivity and enhanced tolerance to salt, drought, and freezing stresses. Interestingly, TaNAC47 overexpression also led to several physiological and biochemical changes, such as changes in the content of soluble sugars and proline, due to the activation of downstream genes such as AtRD29A, AtRD29B, and AtP5CS1; these changes may have enabled the transgenic plants to overcome the stress conditions. Huang et al. [36], also using a transgenic plant approach, found that overexpression of wheat TaNAC29 enhanced drought and salt tolerance in transgenic Arabidopsis plants, indicating the involvement of TaNAC29 in the response to these particular stresses. Moreover, ABA signaling and antioxidant enzymes were found to participate in the TaNAC29-induced stress tolerance processes. Saad et al. [37] improved wheat tolerance to drought and salt stress by introducing the rice stress response NAC gene $S N A C 1$ into wheat under the control of a maize ubiquitin promoter, based on the previous finding that $S N A C 1$ could induce abiotic stress tolerance in rice. Specifically, the transgenic wheat expressing rice $S N A C 1$ had significantly enhanced salinity and drought tolerance over many generations. qRT-PCR results revealed that $S N A C 1$ regulated other genes involved in abiotic/ABA signaling and regulatory components of the ABA receptor. In addition to these responses, wheat $N A C s$ have also been implicated in the response to powdery mildew disease. For example, TaNAC6 overexpression reduced the haustorium quantity of the pathogen and enhanced resistance to the pathogen in transgenic plants [38].

In rice, there are a considerable number of $N A C$ genes involved in response to abiotic as well as biotic stresses. Zhou et al. [38] reported that rice stress-responsive SNAC3 was induced by drought, high temperature, $\mathrm{ABA}$, and salinity stress. In transgenic plants, $S N A C 3$ overexpression improved tolerance to drought, high temperature, and oxidative treatment using methyl viologen. In contrast, suppression of the SNAC3 gene by RNA interference (RNAi) increased sensitivity to these abiotic 
stresses. Strikingly, transgenic plants overexpressing this gene had lower levels of malondialdehyde, hydrogen peroxide $\left(\mathrm{H}_{2} \mathrm{O}_{2}\right)$, and relative electrolyte leakage compared to the wild type control under heat stress treatment. The authors proposed that $S N A C 3$ may confer tolerance to these stresses by modulating ROS homeostasis. Overall, the study demonstrated the crucial role of SNAC3 in response to different stresses and highlighted its potential for engineering crops with improved tolerance to stress such as drought and heat [39]. In addition, overexpression of the ONAC045 gene enhanced drought and salt stress tolerance in transgenic rice plants, consistent with the previous finding that the gene was induced by drought, high salt, low temperature, and ABA stress [40].

In a recent study, four rice NAC genes, ONAC5/6/9, and ONAC10 were overexpressed in rice, which resulted in improved drought tolerance and reduced grain loss under drought stress conditions compared to wild type plants [41]. The authors concluded that ONACs act as the cellular component that regulate many target genes such as TF genes, transmembrane/transporter genes, and auxin/hormone-related genes, which could potentially alter root architecture for drought tolerance [41]. Similarly, ONAC14 overexpression in rice improved drought tolerance, and the transgenic plants had a higher panicle number and filling rate under drought conditions. The overexpression analysis indicated that ONAC14 may mediate drought tolerance through DNA repair and defense responses, based on the findings in transgenic rice [42]. In barley, Chen et al. [43] used the transgenic approach to investigate the functions of HvNAC6 in response to Blumeria graminis f. sp. hordei (Bgh) with respect to the ABA phytohormone. HvNAC6 silencing by RNAi reduced HvNAC6 transcript levels, and the plants were more susceptible to the Bgh pathogen compared to wild type plants.

In contrast to many of the above examples, NAC TFs can also downregulates some stress-related genes. For instance, OsNAC2 overexpression in rice reduced resistance to drought and high salt stress [44]. The study showed that ABA-dependent stress-related genes were downregulated in OsNAC2 overexpression lines. OsNAC2 binds to the cis-element of the stress-related marker genes STRESS-ACTIVATED PROTEIN KINASE1(OsSAPK1) and LATE EMBRYOGENESIS ABUNDANT-3 (OsLEA3) in the abiotic stress and ABA pathways [44]. Focusing on the mechanisms of NAC-mediated disease responses in rice, Liu et al. [45] reported that ONAC66 was significantly induced by blast disease infection. ONAC66 overexpression in rice enhanced resistance to bacterial blight and blast disease, and this enhancement was accompanied by suppressed expression of ABA-related genes. These findings clearly suggested that ONAC66 modulates ABA signaling pathway components to promote disease resistance.

Reports on stress-responsive $N A C$ genes show that they can respond to different stresses in different plant species "systems". Transgenic rice overexpressing the NAC67 gene from finger millet (Eleusine coracana) had enhanced salinity and drought stress tolerance under greenhouse conditions [46]. Specifically, EcNAC67 overexpression in rice helped maintain a high water content and sustainable grain yield under drought conditions, highlighting the potential of using EcNAC67 as a novel gene to improve drought and salinity stress tolerance in rice and other crops. Transgenic Arabidopsis overexpressing maize NAC55 had enhanced drought resistance compared to wild type [47]. Similarly, overexpression of NAC57 from poplar in Arabidopsis plants significantly improved tolerance against salt stress [48].

In conclusion, NAC TFs have been shown to play crucial roles in response to both abiotic and biotic stress. In sorghum, some efforts have been made to decipher the role of NAC genes through genome-wide analysis and expression analysis. However, compared to other cereal crops such as wheat, rice, and maize, there has been less progress in sorghum. For example, in wheat and rice, NAC TFs have been reported extensively. Transgenic approaches have underscored the potential of $N A C$ genes for genetic engineering aimed at enhancing stress tolerance in sorghum and other economically important crops. 


\section{MYB TFs}

Two decades ago, the COLORED1 (C1) gene from Zea mays was the first identified plant MYB gene, and it encodes a MYB domain protein that is essential for anthocyanin biosynthesis in the aleurone of maize [49]. MYB TF characterization is based on the presence of highly conserved MYB domains involved in DNA binding. Generally, these domains contain multiple repeats (R); each repeat corresponds to approximately 52 amino acids and three alpha helices, the second and third of which form a helix-turn-helix (HTH) structure [50]. MYB TFs are classified into four groups according to the number of adjacent repeats in their MYB domains: 1R-MYB (one repeat), R2R3-MYB (two repeats), 3R-MYB (three repeats), and 4R-MYB (four repeats). R2R3-MYB proteins are abundant and specific to plants, with 100 R2R3-MYBs in monocot and dicot genomes. R2R3-MYBs play vital roles in plants, including abiotic and biotic stress response [50]. In foxtail millet, rice, and Arabidopsis, the numbers of MYB members are 209, 183, and 198, respectively [51,52].

MYB functions have been extensively investigated in different plant species, and an extensive review by Ambawat et al. [53] described the roles of MYB TFs in different plant processes, including abiotic and biotic stress response. Another review by Dubos et al. [50] focused on the roles of MYB TFs in Arabidopsis, thoroughly covering their functional characterization and describing how MYBs are key factors in regulating abiotic and biotic stress responses. Given the abundance of research in this area, it is worth highlighting how the functions associated with MYB TFs will help improve stress tolerance in economically important crops. For example, as reviewed by Fang et al. [39], MYB TFs are active factors in abiotic stress signaling; MYBs have been found to regulate downstream genes in response to abiotic stresses, and they potentially act at both the transcriptional and post-transcriptional level. Last but not least, the authors of [54] reviewed the roles of MYB TFs in drought response mechanisms, providing specific examples of MYB functions and discussing the potential application of MYBs.

In sorghum, MYB TFs have been shown to play essential roles in response to both abiotic and biotic stresses. For instance, sorghum responds to attack by the fungal pathogen Colletotrichum sublineolum by generating 3-deoxyanthocyanidin phytoalexins, whose biosynthesis requires the sorghum yellow seed 1 (Y1) MYB TF [54]. Interestingly, transgenic maize expressing this MYB TF gene had induced 3-deoxyanthocyanidin, which enhanced resistance against leaf blight pathogen ingress [55]. Although MYB TFs have been linked to abiotic stress responses in several monocot species, none or few are linked to these stresses in sorghum. Other studies have focused on MYB-regulated biosynthetic pathways, such as that of monolignol. Scully et al. [56] reported that SbMYB60 overexpression activated monolignol biosynthesis in drought-tolerant sorghum. MYB TF genes have also been an area of focus in other cereals. In a study about MYB TF functions in drought stress tolerance in rice [57], the authors reported that a novel gene, OsMYB48-1, was induced by $A B A, \mathrm{H}_{2} \mathrm{O}_{2}$, dehydration, and PEG, and it was slightly expressed under salt and cold stress treatment. Furthermore, transgenic rice plants overexpressing OsMYB48-1 exhibited tolerance to drought and salinity stress. Other findings indicated that the stress response roles of OsMYB48-1 reflect its regulation of early ABA signaling genes, such as OsPP2C68 and OSRK1; late-response genes, such as RAB21, OsLEA3, RAB16C, and RAB16D; and ABA-biosynthesis genes, such as OsNCED4 and OsNCED5. In another study, transgenic maize overexpressing OsMYB55 had improved tolerance to drought and high temperature, which was accompanied by the upregulation of several stress-related genes, based on RNA-sequencing results [58]. More recently, Tang et al. [59] found that OsMYB6 overexpression in rice enhanced tolerance to salt and drought stress compared to wild type plants.

In maize, $22 M Y B$ genes were linked to one or more abiotic stresses, with $16 M Y B$ genes shown to be induced by at least two different stress treatments [60]. Accordingly, these genes may be major factors in the cross-talk between different signal transduction pathways induced by abiotic stresses. ZmMYB30 was induced by four stress treatments, and transgenic Arabidopsis expressing ZmMYB30 had enhanced salt tolerance and increased expression levels of several stress-related genes [59]. Overexpression of 
ZmMYBIF35 in Arabidopsis improved tolerance to chilling stress, and the gene was found to regulate a number of stress-related genes under chilling and oxidative stress conditions [61].

Genome-wide analysis in foxtail millet identified 209 SiMYB genes, and expression profiling for 11 SiMYB genes revealed significant changes in their expression patterns under different abiotic and hormone stress treatments [51]. This study provides a great foundation for future research concerning the functions of $S i M Y B$ genes in response to environmental stresses. In other species, MYB TFs have also been implicated in the response to pathogen attack. In wheat, Shan et al. [62] found that overexpression of the wheat R2R3-MYB TF gene TaRIM1 increased resistance against Rhizoctonia cerealis infection. The authors also showed that TaRIM1 modulated defense gene expression in transgenic wheat plants by binding to the MYB-binding site. An example of MYB TF involvement in the response to insect infestation has been reported in chrysanthemum. The CmMYB19 gene was found to be induced by aphid infestation, and overexpressing CmMYB19 limited aphid proliferation via lignin accumulation in the transgenic plants [63].

In summary, MYB TFs play crucial roles in response to numerous environmental stresses, and the findings from different species have shed light on the how that underlie MYB genes are involved in abiotic and biotic stress responses. Although several $M Y B$ genes have been functionally characterized in model and non-model species, the characterization of these TF genes in sorghum is limited. Genome-wide identification of MYB TFs in sorghum will be critical for understanding their stress-related functions in sorghum and for developing improved varieties.

\section{WRKY TFs}

WRKY TFs compose one of the largest families of transcriptional regulators, and they regulate diverse processes in plants. Since the first WRKY TF was identified from sweet potato (Ipomoea batatas; SPF1) 25 years ago [64], extensive studies have uncovered many features of this TF family. WRKY TFs consist of $\sim 60$ amino acids, with the highly conserved WRKYGQK domain at the N-terminus and a zinc-finger motif at the C-terminus. WRKY TFs are DNA-binding proteins that bind the W-box (TTGACT/C), although other binding sites have been reported $[65,66]$.

WRKY TFs represent an active research area in which significant findings have been reported and extensively reviewed. The comprehensive WRKY TF review by Rushton et al [67] covers their involvement in plant processes including development, seed dormancy, germination, and abiotic and biotic stress responses. Two reviews focused on the roles of plant WRKY TFs in response to abiotic stresses, including drought, salinity, heat, cold, and osmotic stress [68,69]. A recent review by Chen et al. [70] provides a current update on WRKY TFs in model plants and important crops, along with a discussion about how high-throughput technologies have accelerated the study of WRKY TFs. Despite the functional characterization of many WRKYs in model plants and major crops, WRKY TFs in sorghum have not garnered much attention. Here, we describe the current status of the related research in sorghum and briefly touch upon the studies in other important crops, such as maize, rice, and wheat.

The numbers of sorghum WRKY genes in different databases are as follows: 134 in the Plant Transcription Factor Database (http://planttfdb.cbi.pku.edu.cn/index.php?sp=Sbi), 97 in the Joint Genome Institute (JGI) annotation database (https://phytozome.jgi.doe.gov/pz/portal.html), and 94 in grass TFDB (https://grassius.org/grasstfdb.php). In previous studies in both model and non-model plants WRKY, TFs have been reported to improve stress tolerance. Although WRKY TFs are regarded as promising candidates for enhanced tolerance to abiotic and biotic stress in major crop species, very little is known about WRKY genes in sorghum. Thus, the identification and characterization of sorghum WRKY genes will provide the necessary foundation for stress tolerance improvement in this crop species. For comparison, the numbers of WRKY genes identified in different crops based on genome-wide approaches include 107 WRKY genes in wheat [71], 119 in maize [72], 70 in chickpea [73], and 103 in rice [74]. 
Numerous studies have established that WRKY TFs regulate diverse processes and control gene expression through combinations of positive and negative regulation [75]. In Arabidopsis, WRKY13 overexpression enhances cadmium tolerance, attributable in part to WRKY13 binding to the PDR8 gene; the resulting transcriptional regulation leads to a decrease in cadmium accumulation and thus enhanced tolerance [76]. In contrast, WRKY12 negatively regulates cadmium tolerance. WRKY12 represses GSH1 expression by directly binding to the W-box in cis-element, and WRKY12-overexpressing Arabidopsis plants have reduced cadmium tolerance [77]. Similarly, ZmWRKY17 overexpression in Arabidopsis reduces salt stress tolerance and decreased sensitivity to ABA by regulating ABA-dependent and stress-responsive genes [78]. Certain WRKY TFs are known to be involved in the response to drought and heat stress, and studies in the last few years have identified WRKY genes responsible for drought tolerance in different species. He et al. [79] reported that overexpressing wheat WRKY1 and WRKY33 in Arabidopsis enhanced drought and heat tolerance in the transgenic plants. Also, ZmWRKY40-overexpressing transgenic Arabidopsis exhibited significant drought tolerance, through the regulation of ROS and stress-related genes [80]. Beyond the functional characterization of WRKY genes in the model plant Arabidopsis, the functions of many WRKY genes remain to be validated in non-model species. Analysis of TaWRKY2 overexpression in wheat by Gao et al. [81] confirmed that it enhanced drought tolerance and also showed that it increased yield in the transgenic wheat. Similarly, transgenic wheat overexpressing Arabidopsis WRKY30 exhibited drought and heat tolerance, and expression analysis revealed that stress-related genes and enzyme-encoding genes were induced [82]. These findings highlight the important functions of WRKY TFs and raise the prospect of their potential for crop improvement in terms of stress tolerance.

Several recent reports have established that WRKY TFs play significant roles in the regulation of defense responses to pathogen attack. Peng et al. [83] reported that rice WRKY80 and WRKY4 enhance resistance to sheath blight disease in rice: WRKY80 binds to the W-box in the promoter region of WRKY4, which acts as a positive regulatory circuit for rice resistance against Rhizoctonia solani. Using expression analysis, Sureshkumar et al. [84] identified WRKY7, WRKY58, WRKY62, WRKY64, and WRKY76 as highly expressed genes under rice blast disease. In another study, overexpression of rice WRKY 67 enhanced the resistance of transgenic rice plants to two major diseases in rice, blast, and bacterial blight, making WRKY67 an ideal target for rice improvement [85]. In wheat, Wang et al. [86] reported that TaWRKY 62 silencing increased susceptibility to stripe rust disease, whereas TaWRKY49 silencing enhanced resistance to the disease relative to non-silenced plants. The enhanced resistance resulting from TaWRKY 49 silencing was linked to genes responsive to jasmonic acid and salicylic acid, TaPR1.1 and TaAOS, and the ROS-related genes TaCAT and TaPOD, whose expression levels were all suppressed. In contrast, reduced resistance following TaWRKY 62 silencing was related to the high expression of TaPOD and TaPR1.1 and suppression of TaPIE1 and TaAOS [86]. WRKY TFs also involved in the responses to plant viruses, for example, WRKY 8 participates in the response to crucifer-infecting tobacco mosaic virus (TMV-cg) in Arabidopsis by regulating both the ABA and ET signaling pathways to confer resistance against the infection [87] Finally, WRKY TFs may also mediate cross-talk between abiotic and biotic stress response pathways. For example, Lee et al. [88] found that OsWRKY11 can enhance pathogen defense and drought tolerance in rice by modulating abiotic and biotic stress-related genes.

Although a decade has passed since the sequencing of the sorghum genome was completed, very little is known about WRKY TFs in sorghum, in contrast to other crops, in which many WRKY genes have been functionally characterized. Therefore, increased attention and study are needed for sorghum WRKY genes. Increasing progress is being made in important crops such as maize and wheat, representing a shift from research in model plants (Arabidopsis) to crop species. The reported findings provide extensive data about the functional characterization of WRKY TFs under abiotic and biotic stresses. Nevertheless, to actualize the promising potential of WRKY genes for crop improvement, future analyses will need to be performed under field conditions to detect the actual changes in phenotype, agronomic traits, and yield. 


\section{ERF/DREB TFs}

Ethylene-responsive factor/dehydration-responsive element-binding (ERF/DREB) proteins make up a large TF subfamily belonging to the APETALA 2/ethylene-responsive element binding factor (AP2/ERF) TF family, which was first identified in Arabidopsis [89,90]. The ERF/DREB subfamily includes stress-inducible factors, and many of these genes are known to be involved in biotic and abiotic stress responses [34]. ERF/DREB TFs play a vital role in ABA-independent pathways, which regulate stress-induced genes. ERF regulates gene expression by binding to the ethylene-responsive element via the GCC box (AGCCGCC) in the cis-element of target genes, and DREB binds to the (DRE/CRT) cis-acting dehydration-responsive element/C-repeat (TACCGACAT) [89]. These subfamilies are well studied, and many ERF and DREB members have been characterized and reviewed. For example, Mizoi et al. [91] discussed their major functions, with an emphasis on DREB TFs involved in abiotic stress responses.

The complete genome sequences of many crops are now available, and AP2/ERF members have been identified in many species, including $105 E R F$ genes in sorghum [92], 171 in millet [93], and 118 in barley [94]. The expression analysis in sorghum revealed that S6DREB2A and SbDREB2B are upregulated under salt and cadmium stress. Furthermore, the miRNAs have been detected in the target regions of SbDREB2 genes which indicating its roles in post-transcriptional regulation [95]. Transgenic rice plants overexpressing sorghum DREB2 exhibited tolerance to water deficits, and the yield improved in transgenic rice compared to wild type [96]. Using a gene stacking approach in rice, Kudo et al. [97] found that overexpression of both DREB1A and PHYTOCHROME-INTERACTING FACTOR-LIKE1 rice (OsPIL1) improved drought tolerance in transgenic plants, similarly to the DREB1A overexpressor. Notably, abiotic stress-responsive DREB1A downstream genes and OsPIL1-related genes were increased in the double overexpressor. In various model plants and crops, DREB/C-repeat factors (CBFs) have also been found to play an important role in increase stress tolerance, particularly in response to cold stress. In sorghum, transcriptome analysis revealed that DREB/CBFs were differentially regulated in response to cold stress in cold stress genotypes [98]. Similarly, transcriptomic analysis of chilling-tolerant Chinese sorghum showed chilling-induced upregulation of cold-response regulator CBF TFs and genes involved in this regulatory [99].

Transgenic wheat plants overexpressing TaERF3 exhibited significant tolerance to drought and salt stress [100]. In contrast, plants with virus-induced gene silencing (VIGS) of TaERF3 were more sensitive to salt and drought compared to unsilenced plants, and TaERF3 was found to regulate other stress-related genes. Recently, El-Esawi and Alayafi. [101] reported that transgenic cotton plants overexpressing StDREB2 from potato exhibited enhanced drought tolerance. Furthermore, the expression levels of stress-induced genes, such as GhERF2, GhDREB1B, and GhDREB1A, and antioxidant genes were higher in the transgenic cotton plants compared to wild type cotton, indicating that StDREB2 overexpression might enhance drought tolerance through the upregulation of genes that mediate defense mechanisms. A recent study showed that the expression of two DREB/CBF genes (TaDREB3 and TaCBF5L) in transgenic wheat and barley could be modulated by the stress-responsive promoters HDZI-3 and HDZI-4, which are induced by drought and cold. The expression of both genes under these promoters improved tolerance to drought and frost in transgenic barley, and frost tolerance in wheat seedlings [102].

In addition to their roles in abiotic stress tolerance, ERF/DREB factors may also have conserved functions important for the regulation of disease resistance pathways. For example, expression profiling of grape $V v E R F$ showed that it was highly expressed in response to Botrytis cinerea infection [103]. Also, transgenic Arabidopsis overexpressing the VaERF20 gene from Amur grape had enhanced resistance to Pseudomonas syringae and Botrytis cinerea pathogens [104].

The findings summarized above indicate that ERF/DREB TFs have important roles in response to both abiotic and biotic stresses. These previous studies in different plant species provide a solid foundation for the application of ERF TFs to improve plant stress responses. 


\section{7. bZIP TFs}

Basic leucine zipper (bZIP) TFs make up one of the largest TF families. The highly conserved bZIP dimerization domain comprises a basic region and a less conserved leucine zipper domain. The basic region contains a nuclear localization signal followed by approximately 16 amino acid residues with an invariant $\mathrm{N}--\mathrm{x}_{7}-\mathrm{R} / \mathrm{K}$ motif that binds to DNA; the leucine zipper region is responsible for the dimerization ability of bZIP $[105,106]$. Previous reports have shown that bZIP proteins bind specifically to C-box (GACGTC), A-box (TACGTA), G-box (CACGTG), PB-like (TGAAAA), and GLM (GTGAGTCAT) sequences in the cis-element of stress response genes [106]. The different numbers of bZIP members that have been identified in different plants include 92 in sorghum [14], 78 in Arabidopsis [107], 191 in wheat [105], 125 in maize [72], and 63 in sesame [108]. Recently, genome-wide analyses have also been used to identify bZIP TFs in a wider range of species, including cassava, watermelon, and peanut [109-111]. bZIP TFs are associated with different biological activities, including the response to biotic and abiotic stresses [112,113].

In different species, transgenic overexpression of $b Z I P$ genes has been shown to enhance tolerance to abiotic and biotic stresses. For instance, transgenic Arabidopsis plants overexpressing wheat TabZIP60 had significantly improved tolerance to salt, drought, and freezing stresses [114]. The study further showed that TabZIP60 binds to ABA-responsive cis-acting elements (ABREs) of ABA-responsive genes. Similarly, overexpression of the novel wheat gene TaZIP14-B in Arabidopsis conferred tolerance to salt, freezing, and ABA in the transgenic plants [115]. It has been reported that bZIP TFs play a vital role in the ABA signaling pathway. One notable example is the rapid expression increase of the ABA-induced genes LEA and Rab16 in rice plants overexpressing OsbZIP42 [116]. OsbZIP42 overexpression also enhanced the tolerance of the transgenic plants to drought stress, potentially due to the changes in ABA signaling and ABA-dependent modification. bZIP TFs can also play a negative regulatory role by modulating ABA signaling. The expression analysis by Pan et al. [117] showed that the tomato SlbZIP38 gene was downregulated under drought, ABA, and salt stress. Moreover, transgenic tomato plants overexpressing SlbZIP38 had reduced drought and salt tolerance, providing further evidence of the negative regulatory role of SlbZIP38.

Chang et al. [118] used a multigene assembly approach (co-overexpression of two genes) and reported that the overexpression of a constitutively active form OsbZIP46CA1 significantly enhanced drought tolerance in transgenic rice. Rice OsbZIP66 is associated with drought tolerance, and the expression analysis by Yoon et al. [119] showed that expression of the gene was induced by drought, salt, and ABA. Moreover, transgenic rice plants overexpressing OsbZIP66 had enhanced drought tolerance, which was positively correlated with the expression level of OsbZIP66. In another study, overexpression of the EcbZIP17 gene from finger millet in transgenic tobacco plants conferred enhanced tolerance to abiotic stresses and improved plant growth and yield [120].

A few studies have indicated that bZIP TFs are involved in plant responses to pathogen attack. The review by Alves et al. [112] covered the responsiveness of plant bZIP TFs to pathogens and also summarized the interacting partners of bZIPs at the molecular level and the signal transduction pathway during pathogen infection. The review by Noman et al. [121] described plant bZIP TF responses to different pathogens and summarized the known functions of bZIP TFs as positive or negative regulators of resistance to pathogen infection. A research article by Alves et al. [122] described four bZIP genes in soybean (GmbZIPE1, GmbZIPE2, GmbZIP105, and GmbZIP62), and the findings indicated that $b Z I P$ proteins contribute to the defense response against Asian soybean rust disease (ASR) through the expression regulation of ASR-related genes. Expression analysis in cassava revealed that MebZIP3 and MebZIP5 were induced by salicylic acid, hydrogen peroxide, and Xanthomonas axonopodis Pv. manihotis [123]. Additionally, transgenic tobacco overexpressing MebZIP3 and MebZIP5 had improved resistance against cassava bacterial blight disease. In contrast, silencing MebZIP3 and MebZIP5 in transgenic plants reduced the transcript levels of the defense-response genes and led to a disease-sensitive phenotype. Some bZIP TFs play multiple roles and are associated with both biotic and abiotic stresses. For example, transgenic Arabidopsis plants overexpressing CabZIP from 
pepper showed enhanced tolerance to Pseudomonas syringae Pv. tomato DC3000 as well as drought and salt tolerance [124]. Despite the available research showing the involvement of bZIP TF genes in different abiotic and biotic stress responses, many of these genes have yet to be characterized in sorghum. These findings would ultimately help improve the tolerance of sorghum to stress conditions. Additionally, the available research findings on bZIP TFs involved in plant responses to insects and other biotic stresses are relatively limited. Therefore, future studies will need to elucidate the functions of bZIP TFs in response to nematodes and other pests because of their destructive impact on many important crops.

\section{Others}

In addition to the examples of TF functional characterization described above, many other TFs from different families contribute to abiotic and biotic stress responses. For example, heat shock (Hsf) TFs are induced in response to a large number of different stresses. Transgenic Arabidopsis overexpressing $\mathrm{ZmHsf05}$ exhibited enhanced tolerance to heat stress, indicating that ZmHsf plays a vital role in heat response [125]. In sorghum, Gomes et al. [126] identified 25 SbHsf genes using a genome-wide approach, some of which were differentially expressed under drought, cold, and salt stress. Another important group of TFs is the bHLH family, and a recent analysis identified $208 \mathrm{bHLH}$ members in maize [127]. Overexpression of Arabidopsis bHLH122 led to resistance to drought, osmotic stress, and salt stress, and microarray analysis showed that $b H L H 122$ affected the expression of numerous abiotic stress-related genes [128]. Thus, bHLH122 was found to have a positive role in the response to drought, salt, and osmotic stress. Homeodomain-leucine zipper (HD-Zip) TFs similarly have diverse functions in mediating stress response. Moreover, mutations in many genes encoding HD-Zip proteins from several species have been associated with improved agronomical phenotypes [129]. TFs influences the expression of thousands of genes, and the responses of TFs to ABA provide a versatile model for the examination of transcriptional regulation using ChIP-Seq. Song et al. [130] identified 21 ABA-related TFs in Arabidopsis; also, the determinants of combined dynamic TF binding along with hierarchy among TFs were defined. Moreover, new family of transcription regulators that exhibited altered expression in response to ABA and salt stress, and the authors proposed that the ABA response is orchestrated by a handful of master regulators, including TFs. Stress-associated protein (SAP) is also recognized as a key player in multiple stress responses. For example, transgenic plants overexpressing AtSAP13 had significant tolerance to drought, salt, and heavy metals ( $\mathrm{Zn}, \mathrm{Cd}$, and AsIII), and dozens of AP2/EREBP TFs were found to interact with the AtSAP13 promoter [131]. However, many other TF families have yet to be functionally characterized in the context of stress response, such as the homeobox (HB), DNA binding with one finger (Dof), LATERAL ORGAN BOUNDARIES (LBD), and plant-specific WUS homeobox (WOX) families. Overall, the findings in the literature show that many TFs related to stress response have been identified in different species. Nevertheless, there are many TFs that have yet to be identified along with known TFs whose functions are not yet known.

\section{Non-Coding RNAs Regulate Gene Expression}

Non-coding RNAs (ncRNAs) have wide-ranging impacts and have become a major research area. Plant genomes encode millions of ncRNAs, some of which play vital roles in regulating gene expression at the transcriptional and post-transcriptional levels [132]. NcRNAs are classified into different groups based on their length and function. Small RNAs are 20-30 nucleotides in length and include small interfering RNAs and microRNAs (siRNAs and miRNAs). Two other groups are medium-length RNAs, which are 50-200 nucleotides in length, and long ncRNAs (lncRNAs), which are $>200$ nucleotides in length [133]. LncRNAs have garnered much attention, and they are known to have crucial roles in response to abiotic and biotic stresses [134]. Advanced technologies that facilitate genome-wide study, such as RNA-sequencing and next-generation sequencing, have been critical for the identification of lncRNAs in many species, including Arabidopsis, wheat, rice, and maize [135-138]. Boerner et al. [132] reviewed lncRNA identification and characterization as well as the mechanisms 
of microRNAs (miRNAs) and lncRNAs in response to different stresses in plants. Despite their comprehensive summary and explanations of both lncRNA and miRNA functions in response to plant stress, they underscored that more studies are needed to more fully understand the regulatory roles and signaling pathways of ncRNAs in response to stresses. The following paragraphs summarize recent updates on small RNAs and lncRNAs in response to abiotic stresses and current studies investigating these plant responses to disease stress.

Several regulatory small RNAs play important roles in biotic stress response by controlling the expression of TFs. Specifically, these small RNAs modify transcription regulators such as WRKY, NAC and zinc-finger proteins in Arabidopsis through post-transcriptional silencing and signaling via reactive oxygen species [139]. miRNAs and TFs are master regulators, and the combinatorial regulation mediated by TFs and miRNAs guides the proper progression of biological events [140]. In rice, NAC TF genes targeted by miR164 negatively regulate drought tolerance [141]. A MYB TF that is upregulated under heat stress was found to be targeted by miR828 and miR858. In wheat, the regulation of NAC21/22 by miR164 affects the resistance to stripe rust disease [142]. The types of small RNAs (sRNAs) that regulate gene expression in plants include miRNAs and natural antisense miRNAs (nat-miRNAs), and miRNAs have been shown to be involved in the responses to different abiotic and biotic stresses. For instance, in sorghum, 526 novel miRNAs were identified, and 96 were found to be drought-responsive miRNAs [143]. In tomato, stress-responsive miRNAs were recently identified, and 10 miRNAs were found to have stress-specific expression responses [144]. miRNAs are ideal candidates to investigate the crosstalk between gene expression networks and signaling pathways, because many miRNAs target TFs that are master regulators of gene expression [145].

In Arabidopsis, a novel drought-induced lncRNA (DRIR) was identified as a positive regulator of plant responses to salt and drought stresses [146]. Expression profiling revealed that DRIR expression could be significantly induced by drought, salt, and ABA stresses, and its levels were lower under normal conditions. In addition, transgenic plants overexpressing Arabidopsis DRIR had increased drought and salt tolerance.

Using genome-wide transcription analysis in maize, Li et al. [147] identified 1535 drought response lncRNAs. Furthermore, structural characterization showed that lncRNAs are less complex and shorter than protein-coding genes and also have fewer exons. Also, lncRNAs exhibit different expression patterns at different growth stages and in response to drought stress. For example, at the reproductive stage, IncRNAs have an altered expression pattern, and they are more abundant under drought stress. As such, the study by Li et al. [147] provides new insight into lncRNAs involved in gene regulation in the drought response. Similarly, a research study by Nagaraju et al. [148] used deep RNA-sequencing and identified 1710 lncRNAs responsive to salt and boron stress as well as 848 stress-responsive potential trans-natural antisense transcript (NAT) lncRNAs, which were associated with transcription regulation, response to abiotic stimulus and response to stress. These ncRNAs could potentially regulate genes related to transcriptional regulation, abiotic stress response, and other biological functions. In Arabidopsis, NAT-InRNAs were found to acts in cis to activate MAF4 expression during cold stress. The different expression profiles of $M A F 4$ revealed the vital role of lncRNAs in coordinating the vernalization response and in other biological processes [149]. In cassava, systematic screening identified 318 lncRNAs responsive to cold and drought, and they were generally coexpressed concordantly or discordantly with their neighboring genes [150].

Several lncRNAs have been implicated in the regulation of genes in response to biotic stress such as pathogens. Thousands of lncRNAs were identified in rice lines resistant to the rice blast pathogen Magnaporthe oryzae [151]. Functional classification of these lncRNAs showed that the numbers of long intergenic ncRNAs were higher in the resistant rice lines compared to the numbers of antisense lncRNAs. Overall, the findings suggested that lncRNAs have a role in regulating resistance genes in rice during M. oryzae infection [151]. Perotti et al. [152] identified lncRNAs involved in the resistance to fungal disease (Verticillium dahliae) in cotton. The conclusions about the lncRNA functions were based in part on comparisons of the lncRNA expression patterns in disease-resistant cotton (Gossypium barbadense) 
and susceptible cotton (G. hirsutum), which showed clear disease response mechanisms. Interestingly, some lncRNAs may function in multiple stress responses. For example, $125 \operatorname{lncRNAs}$ were found to respond to powdery mildew disease infection and heat stress [135]. The findings from the research study by Dixit et al. [153] included 565 lncRNAs involved in the response to root-knot nematode; 15 lncRNAs were studied further and were found to have different expression patterns.

In summary, remarkable progress has been made in the last few years although studies on small RNAs and lncRNAs in sorghum are limited. Besides TFs, epigenetic manipulation of gene expression is another potential strategy for improving plant responses to abiotic and biotic stresses.

\section{Concluding Remarks and Future Perspectives}

Considering the world's population is expected to reach 9 billion by 2050 [154], new strategies, such as improved stress tolerance in crops, are critical for increasing productivity to satisfy the projected food and energy demands of the world population. As key stress-tolerance mediators, TFs could be manipulated to boost the tolerance of different crops to abiotic and biotic stresses. In the last two decades, there has been significant progress in the identification and characterization of major TF families, such as WRKY, NAC, MYB, DREB, and bZIP, in response to both abiotic and biotic stresses. In this review, we summarized recent reports about stress-induced TFs in the top five cereal crops (wheat, rice, maize, barley, and sorghum), and their potential for sorghum improvement. However, the discussed TF families have been extensively studied in the major crops, in sorghum, the studies are limited on some TF families such WRKY TFs.

Recent reports have shown that TFs are now being validated in both model and non-model plants. However, the majority of these studies are performed in the laboratory, and there is a dire need to test candidate TF genes that may improve tolerance in transgenic plants under field conditions. As shown in the literature, TF responses to stress conditions can be extremely complicated. The overexpression of a single TF gene might promote or suppress a vast array of downstream genes, a single gene might be regulated by different TFs that bind to its cis- elements, and a single TF might respond to different stresses, For example, OsNAC6 was found to improve tolerance to high salt, dehydration, and blast disease in transgenic rice plants. Moreover, OsNAC6 activates the expression of genes that are induce by biotic and abiotic stress, such as AK104277 (peroxidase gene) and $A K 110725$ [25]. In Arabidopsis, 34 TF families are known to contain 1533 TFs; interestingly, 45\% of these TFs are specific to plants [22]. It would be a tremendous challenge to individually characterize millions of TF genes at the molecular level. Therefore, future studies may undertake combinatorial approaches to study multiple TFs and multiple stresses to elucidate the cross-talk among different TFs, as opposed to a single TF and stress. The availability of complete genome sequences for an increasing number of species and breakthroughs in sequencing technology have facilitated the identification and characterization of TFs. Moreover, published genome databases should enable in silico analysis of genome-wide annotation data for the identification of TFs. For example, the ERF gene family was identified using sorghum genomic databases [92]. Genomic identification strategies have benefited tremendously from technologies such as chromatin immunoprecipitation with massively parallel sequencing (CHIP-Seq) and next-generation sequencing (NGS). CRISPR/Cas9 (clustered regularly interspaced short palindromic repeats/CRISPR-associated protein 9) gene editing is a powerful tool that could be used to modulate TFs with the goal of improving plant stress tolerance. A recent publication by Bao et al. [155] provides a comprehensive review on the application of CRISPR/Cas9 for evaluating genes and gene functions involved in environmental stress tolerance or resistance, crop improvement, and the transcriptional and translational regulation of the genes. Future studies will need to address TF gene functional redundancy. Additionally, although previous analyses of TF gene overexpression in response to a specific stress have been highly informative, studies focusing on crop yield and productivity are needed; that is, future investigations will need to address whether the overexpression of stress-related TF genes in transgenic plants improves their stress tolerance and growth and also determine whether there is a negative effect on yield under field conditions. 
Numerous reports have confirmed and characterized the involvement of TFs in response to abiotic and biotic stresses, but the molecular mechanisms of many of these TFs are not understood. Plant TF responses to abiotic and biotic stresses are extremely complex, and several TF families are clearly associated with single or multiple stresses along with complex cross-talk between different signal transduction pathways. Collectively, the findings from previous reports indicate the potential application of TF genes to enhance stress tolerance/resistance in important crops; however, extensive studies are needed to understand the mechanisms of these TFs.

Author Contributions: All authors listed in this paper have made substantial intellectual contributions to the work and approved it for publication.

Funding: This work was generously supported by the project of The National Key Research and Development Program of China (2017YFD0300200) and (2016YFD0100102-11), Innovation Academy for Seed Design, CAS.

Acknowledgments: The authors sincerely thank the Center for Agricultural Resources Research, Institute of Genetics and Developmental Biology (CAS), for providing the facilities. We are thankful to Rae Eden Yumul for editing and useful suggestions. The authors are grateful to the reviewers for their helpful comments and suggestions.

Conflicts of Interest: The authors declare no conflicts of interest.

\section{Abbreviations}

TFs: Transcription Factors; NAC: No apical meristem (NAM), ATAF, and cup-shaped cotyledon (CUC) protein; HTH: helix-turn-helix; TFDB: Transcription factors database; ABA: Abscisic acid; DNA: Deoxyribonucleic acid; ROS: Reactive oxygen species; JA: Jasmonic acid; SA: Salicylic acid; ET: Ethylene; MAPK: Mitogen-activated protein Kinase; CDPK: Calcium-dependent protein kinase; ERF: Ethylene-responsive Factor; DREB: Dehydration-responsive element-binding; bZIP: basic leucine zipper; RNAi: RNA interference; ncRNAs: non-coding RNAs; lncRNAs: Long non-coding RNAs; DRIR: DROUGHT-INDUCED lncRNA; siRNAs: small interfering RNAs; Hsf: heat stress factor; bHLH: basic/helix-loop-helix; HD-Zip: Homeodomain-leucine zipper; SAP: stress-associated protein; AP2/EREBP: APETALA2/Ethylene-responsive element binding protein; Dof: DNA binding with one finger; LBD: LTRAL ORGAN BOUNDARIES; WOX: Plant-specific WUS homeobox family; CHIP-Seq: Chromatin immunopercipitation with massively parallel sequencing; NGS: Next-generation sequencing; CRISPR/Cas9: clustered regularly interspaced short palindromic repeats/CRISPR-associated protein 9; VIGS: Virus-induced gene silencing; TMV-cg: crucifer-infecting tobacco mosaic virus; CBF: C-repeat binding factor; OsPP2C: Oryza sativa protein phosphatase 2C gene; OsNCED: Oryza sativa 9-cis-epoxycarotenoid dioxygenases; OSRK1: protein kinase of Sucrose Non-fermenting 1 protein Kinase2; OsSAPK1: Oryza sativa Stress-activated protein Kinase1; OsLEA3: Oryza sativa late embryonic proteins abundant gene; TaRIM1: Triticum aestivum Rhizoctonia cerealis-induced MYB gene; GSH1: Glutathione cellular protestant gene; TaCAT: Triticum aestivum catalase gene; TaPOD: Triticum aestivum peroxidase gene; TaPR1: Triticum aestivum Pathogen-related gene; TaPIE1: Triticum aestivum pathogen-induced ERF gene; TaAOS: Triticum aestivum allene oxide syntheses gene.

\section{References}

1. Foyer, C.H.; Rasool, B.; Davey, J.W.; Hancock, R.D. Cross-tolerance to biotic and abiotic stresses in plants: A focus on resistance to aphid infestation. J. Exp. Bot. 2016, 67, 2025-2037. [CrossRef] [PubMed]

2. Cohen, S.P.; Leach, J.E. Abiotic and biotic stresses induce a core transcriptome response in rice. Sci. Rep. 2019, 1-11. [CrossRef] [PubMed]

3. Calanca, P.P. Effects of Abiotic Stress in Crop Production, Quantification of Climate Variability, Adaptation and Mitigation for Agricultural Sustainability; Ahmed, M., Stockle, C.O., Eds.; Springer: Cham, Switzerland, 2017; pp. 165-180. [CrossRef]

4. Savary, S.; Ficke, A.; Aubertot, J.N.; Hollier, C. Crop losses due to diseases and their implications for global food production losses and food security. Food Secur. 2012, 4, 519-537. [CrossRef]

5. Ji, Q.; Xu, X.; Wang, K. Genetic transformation of major cereal crops. Int J. Dev. Biol. 2013, 57, 495-508. [CrossRef]

6. Woldesemayat, A.A.; Ntwasa, M. Pathways and Network Based Analysis of Candidate Genes to Reveal Cross-Talk and Specificity in the Sorghum (Sorghum bicolor (L.) Moench) Responses to Drought and It's Co-occurring Stresses. Front. Genet. 2018, 9, 1-22. [CrossRef] [PubMed]

7. Woldesemayat, A.A.; Van Heusden, P.; Ndimba, B.K.; Christoffels, A. An integrated and comparative approach towards identification, characterization and functional annotation of candidate genes for drought tolerance in sorghum (Sorghum bicolor (L.) Moench). BMC Genet. 2017, 18, 1-24. [CrossRef] 
8. Aglawe, S.B.; Fakrudin, B.; Patole, C.B.; Bhairappanavar, S.B.; Koti, R.V.; Krishnaraj, P.U. Quantitative RT-PCR analysis of 20 transcription factor genes of MADS, ARF, HAP2, MBF and HB families in moisture stressed shoot and root tissues of sorghum. Physiol. Mol. Biol. Plants 2012, 18, 287-300. [CrossRef] [PubMed]

9. Johnson, S.M.; Lim, F.-L.; Finkler, A.; Fromm, H.; Slabas, A.R.; Knight, M.R. Transcriptomic analysis of Sorghum bicolor responding to combined heat and drought stress. BMC Genomics 2014, 15, 456. [CrossRef]

10. Erpen, L.; Devi, H.S.; Grosser, J.W.; Dutt, M. Potential use of the DREB/ERF, MYB, NAC and WRKY transcription factors to improve abiotic and biotic stress in transgenic plants. Plant Cell Tissue Organ Cult. 2018, 132, 1-25. [CrossRef]

11. Nath, V.S.; Mishra, A.K.; Kumar, A.; Matousek, J.; Jakse, J. Revisiting the role of transcription factor in coordinating the defense response against Citrus Bark Cracking Viroid infection in commercial hop (Humulus lupulus L.). Viruses J. 2019, 11, 419. [CrossRef]

12. Inukai, S.; Kock, K.H.; Bulyk, M.L. Transcription factor-DNA binding: Beyond binding site motifs. Curr. Opin. Genet. Dev. 2017, 34, 110-119. [CrossRef] [PubMed]

13. Gonzalez, D.H. Plant Transcription Factors: Evolutionary, Structural and Functional Aspects. Plant Transcription Factors: Evolutionary, Structural and Functional Aspects; Elsevier: London, UK, 2015. [CrossRef]

14. Wang, H.; Wang, H.; Shao, H.; Tang, X. Recent Advances in Utilizing Transcription Factors to Improve Plant Abiotic Stress Tolerance by Transgenic Technology. Front. Plant Sci. 2016, 7, 1-13. [CrossRef] [PubMed]

15. Wang, J.; Zhou, J.; Zhang, B.; Vanitha, J.; Ramachandran, S.; Jiang, S.Y. Genome-wide Expansion and Expression Divergence of the Basic Leucine Zipper Transcription Factors in Higher Plants with an Emphasis on Sorghum. J. Integr. Plant Biol. 2011, 53, 212-231. [CrossRef] [PubMed]

16. Hoang, X.L.T.; Nhi, D.N.H.; Thu, N.B.A.; Thao, N.P.; Tran, L.-S.P. Transcription Factors and Their Roles in Signal Transduction in Plants under Abiotic Stresses. Curr. Genomics 2017, 18, 483-497. [CrossRef] [PubMed]

17. Kimotho, N.; Baillo, E.H.; Zhang, Z. Transcription factors involved in abiotic stress responses in maize (Zea mays L.) and their roles in enhanced productivity in the post genomics era Transcription Factors involved in Abiotic stress responses in Maize (Zea mays L.) and their roles in En. Peer J. 2019, 30, e7211. [CrossRef]

18. Hong, Z.; Shikai, L.; Changyou, W.; Wanquan, J. The role of transcription factor in wheat defense against pathogen and its prospect in breeding. J. Plant Biol. Crop Res. 2018, 1, 1005. [CrossRef]

19. Kosová, K.; Vítámvás, P.; Urban, M.O.; Klíma, M.; Roy, A.; Tom Prášil, I. Biological networks underlying abiotic stress tolerance in temperate crops-a proteomic perspective. Int. J. Mol. Sci. 2015, 16, 20913-20942. [CrossRef] [PubMed]

20. Hernandez-Garcia, C.M.; Finer, J.J. Identification and validation of promoters and cis-acting regulatory elements. Plant Sci. 2014, 217, 109-119. [CrossRef]

21. Riechmann, J.L.J.; Heard, G.M.; Reuber, L.; Jiang, C.-Z.; Keddie, J.; Adam, L.; Pineda, O.; Ratcliffe, O.J.; Samaha, R.R.; Creelman, R.; et al. Arabidopsis Transcription Factors: Genome-Wide Comparative Analysis Among Eukaryotes. Science 2000, 290, 2105-2110. [CrossRef]

22. Sablowski, R.W.; Meyerowitz, E.M.; Souer, E.; van Houwelingen, A.; Kloos, D.; Mol, J.; Koes, R. A homolog of NO APICAL MERISTEM is an immediate target of the floral homeotic genes APETALA3/PISTILLATA \rThe no apical meristem gene of Petunia is required for pattern formation in embryos and flowers and is expressed at meristem and primordia boundaries. Cell 1998, 92, 93-103. [CrossRef]

23. Aida, M. Genes Involved in Organ Separation in Arabidopsis: An Analysis of the cup-shaped cotyledon Mutant. Plant Cell Online 1997, 9, 841-857. [CrossRef] [PubMed]

24. Puranik, S.; Sahu, P.P.; Srivastava, P.S.; Prasad, M. NAC proteins: Regulation and role in stress tolerance. Trends Plant Sci. 2012, 17, 369-381. [CrossRef] [PubMed]

25. Nakashima, K.; Tran, L.S.P.; Van Nguyen, D.; Fujita, M.; Maruyama, K.; Todaka, D.; Ito, Y.; Hayashi, N.; Shinozaki, K.; Yamaguchi-Shinozaki, K. Functional analysis of a NAC-type transcription factor OsNAC6 involved in abiotic and biotic stress-responsive gene expression in rice. Plant J. 2007, 51, 617-630. [CrossRef] [PubMed]

26. Nuruzzaman, M.; Manimekalai, R.; Sharoni, A.M.; Satoh, K.; Kondoh, H.; Ooka, H.; Kikuchi, S. Genome-wide analysis of NAC transcription factor family in rice. Gene 2010, 465, 30-44. [CrossRef]

27. Zhang, Y.; Li, D.; Wang, Y.; Zhou, R.; Wang, L.; Zhang, Y.; Yu, J.; Gong, H.; You, J.; Zhang, X. Genome-wide identification and comprehensive analysis of the NAC transcription factor family in Sesamum indicum. PLoS ONE 2018, 13, e0136993. [CrossRef] [PubMed] 
28. Fujita, M.; Fujita, Y.; Maruyama, K.; Seki, M.; Hiratsu, K.; Ohme-Takagi, M.; Tran, L.S.; Yamaguchi-Shinozaki, K.; Shinozaki, K. A dehydration-induced NAC protein, RD26, is involved in a novel ABA-dependent stress-signaling pathway. Plant J. 2004, 39, 863-876. [CrossRef] [PubMed]

29. Tran, L.-S.P. Isolation and Functional Analysis of Arabidopsis Stress-Inducible NAC Transcription Factors That Bind to a Drought-Responsive cis-Element in the early responsive to dehydration stress 1 Promoter. Plant Cell 2004, 16, 2481-2498. [CrossRef] [PubMed]

30. Kadier, Y.; Zu, Y.; Dai, Q.; Song, G.; Lin, S.; Sun, Q.; Lu, M. Genome-wide identification, classification and expression analysis of NAC family of genes in sorghum (Sorghum bicolor (L.) Moench). Plant Growth Regul. 2017, 83, 301-312. [CrossRef]

31. Sanjari, S.; Shirzadian, R.; Zahra, K.; Shobbar, S.; Shahbazi, M. Systematic analysis of NAC transcription factors' gene family and identification of post-flowering drought stress responsive members in sorghum. Plant Cell 2019, 38, 361-376. [CrossRef] [PubMed]

32. Lu, M.; Zhang, D.F.; Shi, Y.S.; Song, Y.C.; Wang, T.Y.; Li, Y. Expression of SbSNAC1, a NAC transcription factor from sorghum, confers drought tolerance to transgenic Arabidopsis. Plant Cell 2013, 115, 443-455. [CrossRef]

33. Lu, M.; Ying, S.; Zhang, D.F.; Shi, Y.S.; Song, Y.C.; Wang, T.Y.; Li, Y. A maize stress-responsive NAC transcription factor, ZmSNAC1, confers enhanced tolerance to dehydration in transgenic Arabidopsis. Plant Cell 2012, 31, 1701-1711. [CrossRef] [PubMed]

34. Zhang, H.; Huang, Y. Genome-wide survey and characterization of greenbug induced NAC transcription factors in sorghum (Sorghum bicolor (L.) Moench). In Proceedings of the XXI Annual International Plant \& Animal Genome Conference, San Diego, CA, USA, 12-16 January 2013; p. 191.

35. Zhang, L.; Zhang, L.; Xia, C.; Zhao, G.; Jia, J.; Kong, X. The Novel Wheat Transcription Factor TaNAC47 Enhances Multiple Abiotic Stress Tolerances in Transgenic Plants. Front. Plant Sci. 2016, 6, 1-12. [CrossRef] [PubMed]

36. Huang, Q.; Wang, Y.; Li, B.; Chang, J.; Chen, M.; Li, K.; Yan, G.; He, G. TaNAC29, a NAC transcription factor from wheat, enhances salt and drought tolerance in transgenic Arabidopsis. BMC Plant Biol. 2015, 15, 1-15. [CrossRef] [PubMed]

37. Saad, A.S.I.; Li, X.; Li, H.P.; Huang, T.; Gao, C.S.; Guo, M.W.; Liao, Y.C. A rice stress-responsive NAC gene enhances tolerance of transgenic wheat to drought and salt stresses. Plant Sci. 2013, 203-204, 33-40. [CrossRef] [PubMed]

38. Zhou, W.; Qian, C.; Li, R.; Zhou, S.; Zhang, R.; Xiao, J.; Cao, A. TaNAC6s are involved in the basal and broad-spectrum resistance to powdery mildew in wheat. Plant Sci. 2018, 277, 218-228. [CrossRef] [PubMed]

39. Fang, Y.; Liao, K.; Du, H.; Xu, Y.; Song, H.; Li, X.; Xiong, L. (A stress-responsive NAC transcription factor SNAC3 confers heat and drought tolerance through modulation of reactive oxygen species in rice. J. Exp. Bot. 2015, 66, 6803-6817. [CrossRef] [PubMed]

40. Zheng, X.; Chen, B.; Lu, G.; Han, B. Overexpression of a NAC transcription factor enhances rice drought and salt tolerance. Biochem. Biophys. Res. Commun. 2009, 379, 985-989. [CrossRef]

41. Chung, P.J.; Jung, H.; Choi, Y.D.; Kim, J. Genome-wide analyses of direct target genes of four rice NAC-domain transcription factors involved in drought tolerance. BMC Genomics 2018, 1-17. [CrossRef]

42. Shim, J.S.; Oh, N.; Chung, P.J.; Kim, Y.S.; Choi, Y.D.; Kim, J. Overexpression of OsNAC14 Improves Drought Tolerance in Rice. Front. Plant Sci. 2018, 9, 1-14. [CrossRef]

43. Chen, Y.J.; Perera, V.; Christiansen, M.W.; Holme, I.B.; Gregersen, P.L.; Grant, M.R.; Collige, G.D.; Lyngkjær, M.F. The barley HvNAC6 transcription factor affects ABA accumulation and promotes basal resistance against powdery mildew. Plant Mol. Biol. 2013, 83, 577-590. [CrossRef]

44. Shen, J.; Lv, B.; Luo, L.; He, J.; Mao, C.; Xi, D.; Ming, F. The NAC-type transcription factor OsNAC2 regulates ABA-dependent genes and abiotic stress tolerance in rice. Sci. Rep. 2017, 7. [CrossRef]

45. Liu, Q.; Yan, S.; Huang, W.; Yang, J.; Dong, J.; Zhang, S.; Zhao, J.; Yang, T.; Mao, X.; Zhu, X.; et al. NAC transcription factor ONAC066 positively regulates disease resistance by suppressing the ABA signaling pathway in rice. Plant Mol. Biol. 2018, 98, 289-302. [CrossRef]

46. Rahman, H.; Ramanathan, V.; Nallathambi, J.; Duraialagaraja, S.; Muthurajan, R. Over-expression of a NAC 67 transcription factor from finger millet (Eleusine coracana L.) confers tolerance against salinity and drought stress in rice. BMC Biotechnol. 2016, 16. [CrossRef] 
47. Mao, H.; Yu, L.; Han, R.; Li, Z.; Liu, H. ZmNAC55, a maize stress-responsive NAC transcription factor, confers drought resistance in transgenic Arabidopsis. Plant Physiol. Biochem. 2016, 105, 55-66. [CrossRef]

48. Yao, W.; Zhao, K.; Cheng, Z.; Li, X.; Zhou, B.; Jiang, T. Transcriptome Analysis of Poplar Under Salt Stress and Over-Expression of Transcription Factor NAC57 Gene Confers Salt Tolerance in Transgenic Arabidopsis. Front. Plant Sci. 2018, 9. [CrossRef]

49. Paz-ares, J.; Ghosal, D.; Wienand, U.; Petersont, A.; Saedler, H. Products and With Structural Similarities. EMBO J. 1987, 6, 3553-3558. [CrossRef]

50. Dubos, C.; Stracke, R.; Grotewold, E.; Weisshaar, B.; Martin, C.; Lepiniec, L. MYB transcription factors in Arabidopsis. Trends Plant Sci. 2010, 15, 573-581. [CrossRef]

51. Muthamilarasan, M.; Khandelwal, R.; Yadav, C.B.; Bonthala, V.S.; Khan, Y.; Prasad, M. Identification and Molecular Characterization of MYB Transcription Factor Superfamily in C4Model Plant Foxtail Millet (Setaria italica L.). PLoS ONE 2014, 9, e109920. [CrossRef]

52. Yanhui, C.; Xiaoyuan, Y.; Kun, H.; Meihua, L.; Jigang, L.; Zhaofeng, G.; Zhiqiang, L.; Yunfei, Z.; Xiaoxiao, W.; Xiaoming, Q.; et al. The MYB transcription factor superfamily of Arabidopsis: Expression analysis and phylogenetic comparison with the rice MYB family. Plant Mol. Biol. 2006, 60, 107-124. [CrossRef]

53. Ambawat, S.; Sharma, P.; Yadav, N.R.; Yadav, R.C. MYB transcription factor genes as regulators for plant responses: An overview. Physiol. Mol. Biol. Plants 2013, 19, 307-321. [CrossRef]

54. Baldoni, E.; Genga, A.; Cominelli, E. Plant MYB transcription factors: Their role in drought response mechanisms. Int. J. Mol. Sci. 2015, 16, 15811-15851. [CrossRef]

55. Ibraheem, F.; Gaffoor, I.; Tan, Q.; Shyu, C.R.; Chopra, S. A sorghum MYB transcription factor induces 3-deoxyanthocyanidins and enhances resistance against leaf blights in maize. Molecules 2015, 20, 2388-2404. [CrossRef]

56. Scully, E.D.; Gries, T.; Sarath, G.; Palmer, N.A.; Baird, L.; Serapiglia, M.J.; Dien, B.S.; Boateng, A.A.; Ge, Z.; Funnell-Harris, D.L.; et al. Overexpression of SbMyb60 impacts phenylpropanoid biosynthesis and alters secondary cell wall composition in Sorghum bicolor. Plant J. 2016, 85, 378-395. [CrossRef]

57. Xiong, H.; Li, J.; Liu, P.; Duan, J.; Zhao, Y.; Guo, X.; Li, Y.; Zhang, H.; Li, Z. Overexpression of OsMYB48-1, a novel MYB-related transcription factor, enhances drought and salinity tolerance in rice. PLoS ONE 2014, 9, e92913. [CrossRef]

58. Casaretto, J.A.; El-Kereamy, A.; Zeng, B.; Stiegelmeyer, S.M.; Chen, X.; Bi, Y.M.; Rothstein, S.J. Expression of OsMYB55 in maize activates stress-responsive genes and enhances heat and drought tolerance. BMC Genomics 2016, 17, 1-15. [CrossRef]

59. Tang, Y.; Bao, X.; Zhi, Y.; Wu, Q.; Guo, Y.; Yin, X.; Zeng, L.; Li, J.; Zhang, J.; He, W.; et al. Overexpression of a MYB Family Gene, OsMYB6, Increases Drought and Salinity Stress Tolerance in Transgenic Rice. Front. Plant Sci. 2019, 10, 1-12. [CrossRef]

60. Chen, Y.H.; Cao, Y.Y.; Wang, L.J.; Li, L.M.; Yang, J.; Zou, M.X. Identification of MYB transcription factor genes and their expression during abiotic stresses in maize. Biol. Plant 2018, 62, 222-230. [CrossRef]

61. Meng, C.; Sui, N. Overexpression of maize MYB-IF35 increases chilling tolerance in Arabidopsis. Plant Physiol. Biochem. 2018, 135, 167-173. [CrossRef]

62. Shan, T.; Rong, W.; Xu, H.; Du, L.; Liu, X.; Zhang, Z. The wheat R2R3-MYB transcription factor TaRIM1 participates in resistance response against the pathogen Rhizoctonia cerealis infection through regulating defense genes. Sci. Rep. 2016, 6, 1-14. [CrossRef]

63. Wang, Y.; Sheng, L.; Zhang, H.; Du, X.; An, C.; Xia, X.; Chen, F.; Jiang, J.; Chen, S. CmMYB19 over-expression improves aphid tolerance in chrysanthemum by promoting lignin synthesis. Int. J. Mol. Sci. 2017, 18, 619. [CrossRef]

64. Ishiguro, S.; Nakamura, K. Characterization of a cDNA encoding a novel DNA-binding protein, SPF1, that recognizes SP8 sequences in the $5^{\prime}$ upstream regions of genes coding for sporamin and $\beta$-amylase from sweet potato. MGG Mol. Gen. Genet. 1994, 244, 563-571. [CrossRef]

65. Cai, M.; Qiu, D.; Yuan, T.; Ding, X.; Li, H.; Duan, L.; Xu, C.; Li, X.; Wang, S. Identification of novel pathogen-responsive cis-elements and their binding proteins in the promoter of OsWRKY13, a gene regulating rice disease resistance. Plant Cell Environ. 2008, 31, 86-96. [CrossRef]

66. Van Verk, M.C.; Pappaioannou, D.; Neeleman, L.; Bol, J.F.; Linthorst, H.J.M. A Novel WRKY Transcription Factor Is Required for Induction of PR-1a Gene Expression by Salicylic Acid and Bacterial Elicitors. Plant Physiol. 2008, 146, 1983-1995. [CrossRef] 
67. Rushton, P.J.; Somssich, I.E.; Ringler, P.; Shen, Q.J. WRKY transcription factors. Trends Plant Sci. 2010, 15, 247-258. [CrossRef]

68. Bakshi, M.; Oelmüller, R. Wrky transcription factors jack of many trades in plants. Plant Signal. Behav. 2014, 9, 1-18. [CrossRef]

69. Chen, L.; Song, Y.; Li, S.; Zhang, L.; Zou, C.; Yu, D. The role of WRKY transcription factors in plant abiotic stresses. Biochim. Biophys. Acta Gene Regul. Mech. 2012, 1819, 120-128. [CrossRef]

70. Chen, F.; Hu, Y.; Vannozzi, A.; Wu, K.; Cai, H.; Qin, Y.; Mullis, A.; Lin, Z.; Zhang, L. The WRKY Transcription Factor Family in Model Plants and Crops. Crit. Rev. Plant Sci. 2017, 36, 311-335. [CrossRef]

71. Gupta, S.; Mishra, V.K.; Kumari, S.; Raavi Chand, R.; Varadwaj, P.K. Deciphering genome-wide WRKY gene family of Triticum aestivum L. and their functional role in response to Abiotic stress. Genes Genomics 2019, 41, 79-94. [CrossRef]

72. Wei, K.F.; Chen, J.; Chen, Y.F.; Wu, L.J.; Xie, D.X. Molecular phylogenetic and expression analysis of the complete WRKY transcription factor family in maize. DNA Res. 2012, 19, 153-164. [CrossRef]

73. Waqas, M.; Azhar, M.T.; Rana, I.A.; Azeem, F.; Ali, M.A.; Nawaz, M.A.; Chuang, G.; Atif, R.M. Genome-wide identification and expression analyses of WRKY transcription factor family members from chickpea (Cicer arietinum L.) reveal their role in abiotic stress-responses. Gene Genomics 2019, 41, 467-481. [CrossRef]

74. Ramamoorthy, R.; Jiang, S.Y.; Kumar, N.; Venkatesh, P.N.; Ramachandran, S. A comprehensive transcriptional profiling of the WRKY gene family in rice under various abiotic and phytohormone treatments. Plant Cell Physiol. 2008, 49, 865-879. [CrossRef]

75. Bakshi, M.; Oelmüller, R. WRKY transcription factors, Plant Signalling and Behavior. J. Plant Signal. Behav. 2014, 9, e27700. [CrossRef]

76. Sheng, Y.; Yan, X.; Huang, Y.; Han, Y.; Zhang, C.; Ren, Y.; Fan, T.; Xiao, F.; Cao, S. The WRKY transcription factor, WRKY13, activates PDR8 expression to positively regulate cadmium tolerance in Arabidopsis. Plant Cell Environ. 2018, 42, 891-903. [CrossRef]

77. Cao, S.; Wu, X.; Ouyang, J.; Jiang, L.; Zhu, X.; Fan, T.; Han, Y. WRKY12 represses GSH1 expression to negatively regulate cadmium tolerance in Arabidopsis. Plant Mol. Biol. 2019, 99, 149-159. [CrossRef]

78. Cai, R.; Dai, W.; Zhang, C.; Wang, Y.; Wu, M.; Zhao, Y.; Ma, Q.; Xiang, Y.; Cheng, B. The maize WRKY transcription factor ZmWRKY17 negatively regulates salt stress tolerance in transgenic Arabidopsis plants. Planta 2017, 246, 1215-1231. [CrossRef]

79. He, G.H.; Xu, J.Y.; Wang, Y.X.; Liu, J.M.; Li, P.S.; Chen, M.; Ma, Y.Z.; Xu, Z.S. Drought-responsive WRKY transcription factor genes TaWRKY1 and TaWRKY33 from wheat confer drought and/or heat resistance in Arabidopsis. BMC Plant Biol. 2016, 16, 1-16. [CrossRef]

80. Wang, C.T.; Ru, J.N.; Liu, Y.W.; Yang, J.F.; Li, M.; Xu, Z.S.; Fu, J.D. The Maize WRKY Transcription Factor ZmWRKY40 Confers Drought Resistance in Transgenic Arabidopsis. Int. J. Mol. Sci. 2018, 19, 2580. [CrossRef]

81. Gao, H.; Wang, Y.; Xu, P.; Zhang, Z. Overexpression of a WRKY Transcription Factor TaWRKY2 Enhances Drought Stress Tolerance in Transgenic Wheat. Front. Plant Sci. 2018, 9, 997. [CrossRef]

82. El-Esawi, M.A.; Al-Ghamdi, A.A.; Ali, H.M.; Ahmad, M. Overexpression of AtWRKY30 Transcription Factor Enhances Heat and Drought Stress Tolerance in Wheat (Triticum aestivum L.). Genes 2019, 10, 163. [CrossRef]

83. Peng, X.; Wang, H.; Jang, J.C.; Xiao, T.; He, H.; Jiang, D.; Tang, X. OsWRKY80-OsWRKY4 Module as a Positive Regulatory Circuit in Rice Resistance Against Rhizoctonia solani. Rice 2016, 9. [CrossRef]

84. Sureshkumar, V.; Dutta, B.; Kumar, V.; Prakash, G.; Mishra, D.C.; Chaturvedi, K.K.; Solanke, A.U. Multilocus phylogeny, species delimitation and biogeography of Iberian valvatiform springsnails (Caenogastropoda: Hydrobiidae), with the description of a new genus. Zool. J. Linn. Soc. 2019, 1-13. [CrossRef]

85. Yang, T.; Zhu, X.; Yang, J.; Li, X.; Dong, J.; Zhang, S.; Zhao, J.; Yang, T.; Mao, X.; Zhu, X.; et al. OsWRKY67 positively regulates blast and bacteria blight resistance by direct activation of PR genes in rice. BMC Plant Biol. 2018, 18, 1-13. [CrossRef]

86. Wang, J.; Tao, F.; Tian, W.; Guo, Z.; Chen, X.; Xu, X.; Shang, H.; Hu, X. The wheat WRKY transcription factors TaWRKY49 and TaWRKY62 confer differential high-temperature seedling-plant resistance to Puccinia striiformis f. sp. tritici. PLoS ONE 2017, 12, e0181963. [CrossRef]

87. Chen, L.; Zhang, L.; Li, D.; Wang, F.; Yu, D. WRKY8 transcription factor functions in the TMV-cg defense response by mediating both abscisic acid and ethylene signaling in Arabidopsis. Proc. Natl. Acad. Sci. USA 2013, 110. [CrossRef] 
88. Lee, H.; Cha, J.; Choi, C.; Choi, N.; Ji, J.; Park, S.; Lee, S.; Hwang, D. Rice WRKY11 Plays a Role in Pathogen Defense and Drought Tolerance. Rice 2018, 11. [CrossRef]

89. Jofuku, K.D.; den Boer, B.G.W.; Montagu, M.; Okamuro, J.K. Control of Arabidopsis Flower and Seed Development by the Homeotic Gene APETALA2. Plant Cell 2007, 6, 1211. [CrossRef]

90. Sakuma, Y.; Liu, Q.; Dubouzet, J.G.; Abe, H.; Yamaguchi-Shinozaki, K.; Shinozaki, K. DNA-binding specificity of the ERF/AP2 domain of Arabidopsis DREBs, transcription factors involved in dehydration- and cold-inducible gene expression. Biochem. Biophys. Res. Commun. 2002, 290, 998-1009. [CrossRef]

91. Mizoi, J.; Shinozaki, K.; Yamaguchi-Shinozaki, K. AP2/ERF family transcription factors in plant abiotic stress responses. Biochim. Biophys. Acta Gene Regul. Mech. 2012, 1819, 86-96. [CrossRef]

92. Yan, H.W.; Hong, L.; Zhou, Y.Q.; Jiang, H.Y.; Zhu, S.W.; Fan, J.; Cheng, B.J. A genome-wide analysis of the ERF gene family in sorghum. Genet. Mol. Res. 2013, 12, 2038-2055. [CrossRef]

93. Lata, C.; Mishra, A.K.; Muthamilarasan, M.; Bonthala, V.S.; Khan, Y.; Prasad, M. Genome-Wide Investigation and Expression Profiling of AP2/ERF Transcription Factor Superfamily in Foxtail Millet (Setaria italica L.). PLoS ONE 2014, 9, e113092. [CrossRef]

94. Guo, B.; Wei, Y.; Xu, R.; Lin, S.; Luan, H.; Lv, C.; Zhang, X.; Song, X.; Xu, R. Genome-wide analysis of APETALA2/ethylene-responsive factor (AP2/ERF) Gene family in barley (Hordeum vulgare L.). PLoS ONE 2016, 11, e0161322. [CrossRef]

95. Akbudak, M.A.; Filiz, E.; Kontbay, K. DREB2 (dehydration-responsive element-binding protein 2) type transcription factor in sorghum (Sorghum bicolor): Genome-wide identification, characterization and expression profiles under cadmium and salt stresses. Biotech 2018, 8, 426. [CrossRef]

96. Bihani, P.; Char, B.; Bhargava, S. Transgenic expression of sorghum DREB2 in rice improves tolerance and yield under water limitation. J. Agric. Sci. 2011, 149, 95-101. [CrossRef]

97. Kudo, M.; Kidokoro, S.; Yoshida, T.; Mizoi, J.; Todaka, D.; Fernie, A.R.; Shinozaki, K.; Yamaguchi-Shinozaki, K. Double overexpression of DREB and PIF transcription factors improves drought stress tolerance and cell elongation in transgenic plants. Plant Biotechnol. J. 2017, 15, 458-471. [CrossRef]

98. Chopra, R.; Burow, G.; Hayes, C.; Emendack, Y.; Xin, Z.; Burke, J. Transcriptome profiling and validation of gene based single nucleotide polymorphisms (SNPs) in sorghum genotypes with contrasting responses to cold stress. BMC Genomics 2015, 16,1-11. [CrossRef]

99. Marla, S.R.; Shiva, S.; Welti, R.; Liu, S.; Burke, J.J.; Morris, G.P. Comparative transcriptome and lipidome analyses reveal molecular chilling responses in chilling-tolerant sorghums. Plant Genome 2017, 10, 1-16. [CrossRef]

100. Wang, A.; Ye, X.; Qi, L.; Zhang, Z.; Liang, H.; Xin, Z.; Du, L. The ERF transcription factor TaERF3 promotes tolerance to salt and drought stresses in wheat. Plant Biotechnol. J. 2014, 12, 468-479. [CrossRef]

101. El-Esawi, M.; Alayafi, A. Overexpression of StDREB2 Transcription Factor Enhances Drought Stress Tolerance in Cotton (Gossypium barbadense L.). Genes 2019, 10, 142. [CrossRef]

102. Yang, Y.; Al-Baidhani, H.H.J.; Harris, J.; Riboni, M.; Li, Y.; Mazonka, I.; Bazanova, N.; Chirkova, L.; Hussain, S.S.; Hrmova, M.; et al. DREB/CBF expression in wheat and barley using the stress-inducible promoters of HD-Zip I genes: Impact on plant development, stress tolerance and yield. Plant Biotechnol. J. 2019, 1-2. [CrossRef]

103. Zhu, Y.; Li, Y.; Zhang, S.; Zhang, X.; Yao, J.; Luo, Q.; Wang, X. Genome-wide identification and expression analysis reveal the potential function of ethylene responsive factor gene family in response to Botrytis cinerea infection and ovule development in grapes (Vitis vinifera L.). Plant Biol. 2018. [CrossRef]

104. Wang, M.; Zhu, Y.; Han, R.; Yin, W.; Guo, C.; Li, Z.; Wang, X. (Expression of vitis amurensis VaERF20 in Arabidopsis thaliana improves resistance to botrytis cinerea and pseudomonas syringae pv. Tomato DC3000. Int. J. Mol. Sci. 2018, 19. [CrossRef]

105. Agarwal, P.; Baranwal, V.K.; Khurana, P. Genome-wide Analysis of bZIP Transcription Factors in wheat and Functional Characterization of a TabZIP under Abiotic Stress. Sci. Rep. 2019, 9, 1-18. [CrossRef]

106. Ali, Z.; Sarwat, S.S.; Karim, I.; Jaskani, M.J.; Khan, A.A. Functions of plant's bZIP transcription factors. Pak. J. Agric. Sci. 2016, 53, 303-314. [CrossRef]

107. Dröge-Laser, W.; Snoek, B.L.; Snel, B.; Weiste, C. The Arabidopsis bZIP transcription factor family-An update. Curr. Opin. Plant Biol. 2018, 45, 36-49. [CrossRef] 
108. Manoli, A.; Trevisan, S.; Quaggiotti, S.; Varotto, S. Identification and characterization of the BZR transcription factor family and its expression in response to abiotic stresses in Zea mays L. Plant Growth Regul. 2018, 84, 423-436. [CrossRef]

109. Hu, W.; Yang, H.; Yan, Y.; Wei, Y.; Tie, W.; Ding, Z.; Zuo, J. Genome-wide characterization and analysis of bZIP transcription factor gene family related to abiotic stress in cassava. Nature 2016, 7, 22783. [CrossRef]

110. Mehmet, N.; Fadime, U.; Yasin, C.; Yasemin, K.; Altunoglu, C.; Cengiz, M. Comparative identification, characterization, and expression analysis of bZIP gene family members in watermelon and melon genomes. Plant. Growth Regul. 2018, 87, 227-243. [CrossRef]

111. Wang, Z.; Yan, L.; Wan, L.; Huai, D.; Kang, Y.; Shi, L.; Jiang, Y.; Lei, Y. Genome-wide systematic characterization of bZIP transcription factors and their expression profiles during seed development and in response to salt stress in peanut. BMC Genomics 2019, 20,1-14. [CrossRef]

112. Alves, M.S.; Dadalto, S.P.; Gonçalves, A.B.; De Souza, G.B.; Barros, V.A.; Fietto, L.G. Plant bZIP transcription factors responsive to pathogens: A review. Int. J. Mol. Sci. 2013, 14, 7815-7828. [CrossRef]

113. Sornaraj, P.; Luang, S.; Lopato, S.; Hrmova, M. Basic leucine zipper (bZIP) transcription factors involved in abiotic stresses: A molecular model of a wheat bZIP factor and implications of its structure in function. Biochim. Biophys. Acta 2016, 1860, 46-56. [CrossRef]

114. Zhang, L.; Zhang, L.; Xia, C.; Zhao, G.; Liu, J.; Jia, J. A novel wheat bZIP transcription factor, TabZIP60, confers multiple abiotic stress tolerances in transgenic Arabidopsis. Physiol. Plant. 2015. [CrossRef]

115. Zhang, L.; Zhang, L.; Xia, C.; Gao, L.; Hao, C. A Novel Wheat C-bZIP Gene, TabZIP14-B, Participates in Salt and Freezing Tolerance in Transgenic Plants. Front. Plant Sci. 2017, 8, 1-11. [CrossRef] [PubMed]

116. Joo, J.; Hab, Y.; Sang, L.; Song, I. OsbZIP42 is a positive regulator of ABA signaling and confers drought tolerance to rice. Planta 2019, 249. [CrossRef] [PubMed]

117. Pan, Y.; Hu, X.; Li, C.; Xu, X.; Su, C.; Li, J.; Song, H.; Zhang, H.; Pan, Y. SlbZIP38, a Tomato bZIP Family Gene Downregulated by Abscisic Acid, Is a Negative Regulator of Drought and Salt Stress Tolerance. Genes 2017, 8, 402. [CrossRef] [PubMed]

118. Chang, Y.; Nguyen, B.H.; Xie, Y.; Xiao, B.; Tang, N.; Zhu, W.; Mou, T.; Xiong, L. Co-overexpression of the Constitutively Active Form of OsbZIP46 and ABA-Activated Protein Kinase SAPK6 Improves Drought and Temperature Stress Resistance in Rice. Front. Plant Sci. 2017, 8, 1-16. [CrossRef] [PubMed]

119. Yoon, S.; Lee, D.K.; Yu, I.J.; Kim, Y.S.; Choi, Y.D.; Kim, J.K. Overexpression of the OsbZIP66 transcription factor enhances drought tolerance of rice plants. Plant Biotechnol. Rep. 2017, 11, 53-62. [CrossRef]

120. Ramakrishna, C.; Singh, S.; Raghavendrarao, S.; Padaria, J.C.; Mohanty, S.; Sharma, T.R.; Solanke, A.U. The membrane tethered transcription factor EcbZIP17 from finger millet promotes plant growth and enhances tolerance to abiotic stresses. Sci. Rep. 2018, 8, 1-14. [CrossRef] [PubMed]

121. Noman, A.; Liu, Z.; Aqeel, M.; Zainab, M.; Khan, M.I.; Hussain, A.; Ashraf, M.F.; Li, X.; Weng, Y.; He, S. Basic leucine zipper domain transcription factors: The vanguards in plant immunity. Biotechnol. Lett. 2017, 39, 1779-1791. [CrossRef]

122. Alves, M.S.; Soares, Z.G.; Vidigal, P.M.P.; Barros, E.G.; Poddanosqui, A.M.P.; Aoyagi, L.N.; Abdelnoor, R.V.; Marcelino-Gumaraes, F.C.; Fietto, L.G. Differential expression of four soybean bZIP genes during Phakopsora pachyrhizi infection. Funct. Integr. Genomic 2015, 15, 685-696. [CrossRef]

123. Li, X.; Fan, S.; Hu, W.; Liu, G.; Wei, Y.; He, C.; Shi, H. Two Cassava Basic Leucine Zipper (bZIP) Transcription Factors (MebZIP3 and MebZIP5) Confer Disease Resistance against Cassava Bacterial Blight. Front. Plant Sci. 2017, 8, 1-11. [CrossRef]

124. Lee, S.C.; Choi, H.W.; Hwang, I.S.; Choi, D.S.; Hwang, B.K. Functional roles of the pepper pathogen-induced bZIP transcription factor, CAbZIP1, in enhanced resistance to pathogen infection and environmental stresses. Planta 2006, 224, 1209-1225. [CrossRef] [PubMed]

125. Wang, J.; Meng, X.; Dobrovolskaya, O.B.; Orlov, Y.L.; Chen, M. Non-coding RNAs and Their Roles in Stress Response in Plants. Genomics Proteomics Bioinform. 2017, 15, 301-312. [CrossRef] [PubMed]

126. Gomes, A.Q.; Nolasco, S.; Soares, H. Non-coding RNAs: Multi-tasking molecules in the cell. Int. J. Mol. Sci. 2013, 14, 16010-16039. [CrossRef] [PubMed]

127. Sun, X.; Zheng, H.; Sui, N. Regulation mechanism of long non-coding RNA in plant response to stress. Biochem. Biophys. Res. Commun. 2018, 503, 402-407. [CrossRef] 
128. Di, C.; Yuan, J.; Wu, Y.; Li, J.; Lin, H.; Hu, L.; Zhang, T.; Qi, Y.; Gerstein, M.B.; Guo, Y. Characterization of stress-responsive lncRNAs in Arabidopsis thaliana by integrating expression, epigenetic and structural features. Plant J. 2014, 80, 848-861. [CrossRef]

129. Lu, T.; Zhu, C.; Lu, G.; Guo, Y.; Zhou, Y.; Zhang, Z.; Zhao, Y.; Li, W.; Lu, Y.; Tang, W.; et al. Strand-specific RNA-seq reveals widespread occurrence of novel cis-natural antisense transcripts in rice. BMC Genomics 2012, 13. [CrossRef]

130. Song, L.; Huang, S.S.C.; Wise, A.; Castanoz, R.; Nery, J.R.; Chen, H.; Watanabe, M.; Thomas, J.; Bar-Joseph, Z.; Ecker, J.R. A transcription factor hierarchy defines an environmental stress response network. Science 2016, 354. [CrossRef]

131. Xin, M.; Wang, Y.; Yao, Y.; Song, N.; Hu, Z.; Qin, D.; Xie, C.; Peng, H.; Ni, Z.; Sun, Q. Identification and characterization of wheat long non-protein coding RNAs responsive to powdery mildew infection and heat stress by using microarray analysis and SBS sequencing. BMC Plant Biol. 2011, 11. [CrossRef]

132. Boerner, S.; McGinnis, K.M. Computational identification and functional predictions of long noncoding RNA in Zea mays. PLoS ONE 2012, 7, e43047. [CrossRef]

133. Qin, T.; Zhao, H.; Cui, P.; Albesher, N.; Xiong, L. A Nucleus-Localized Long Non-Coding RNA Enhances Drought and Salt Stress Tolerance. Plant Physiol. 2017, 175, 1321-1336. [CrossRef]

134. Pang, J.; Zhang, X.; Ma, X.; Zhao, J. Spatio-Temporal Transcriptional Dynamics of Maize Long Non-Coding RNAs Responsive to Drought Stress. Genes 2019, 10, 138. [CrossRef] [PubMed]

135. Huanca-Mamani, W.; Arias-Carrasco, R.; Cárdenas-Ninasivincha, S.; Rojas-Herrera, M.; Sepúlveda-Hermosilla, G.; Caris-Maldonado, J.C.; Maracaja-Coutinho, V. Long non-coding RNAs responsive to salt and boron stress in the hyper-arid lluteño maize from atacama desert. Genes 2018, 9, 170. [CrossRef] [PubMed]

136. Li, S.; Yu, X.; Lei, N.; Cheng, Z.; Zhao, P.; He, Y.; Wang, W.; Peng, M. Genome-wide identification and functional prediction of cold and/or drought-responsive lncRNAs in cassava. Sci. Rep. 2017, 7, 1-15. [CrossRef] [PubMed]

137. Jain, P.; Sharma, V.; Dubey, H.; Singh, P.K.; Kapoor, R.; Kumari, M.; Singh, J. Open access Identification of long non-coding RNA in rice lines resistant to Rice blast pathogen Maganaporthe oryzae. Bioinformation 2017, 13, 249-255. [CrossRef] [PubMed]

138. Zhang, L.; Wang, M.; Li, N.; Wang, H.; Qiu, P.; Pei, L.; Xu, Z.; Wang, T.; Gao, E.; Liu, J.; et al. Long noncoding RNAs involve in resistance to Verticillium dahliae, a fungal disease in cotton. Plant Biotechnol. J. 2018, 16, 1172-1185. [CrossRef] [PubMed]

139. Golldack, D.; Lüking, I.; Yang, O. Plant tolerance to drought and salinity: Stress regulating transcription factors and their functional significance in the cellular transcriptional network. Plant Cell Rep. 2011, 30, 1383-1391. [CrossRef] [PubMed]

140. Jangra, S.; Chaudary, V.; Yadav, N.R. Transcription factor and microRNA interplay: A new strategy for crop improvement. Intech 2016, 13. [CrossRef]

141. Fang, Y.; Xie, K.; Xiong, L. Conserved miR164-targeted NAC genes negatively regulate drought resistance in rice. J. Exp. Bot. 2014, 65, 2119-2135. [CrossRef] [PubMed]

142. Feng, H.; Duan, X.; Zhang, Q.; Li, X.; Wang, B.; Huang, L.; Wang, X.; Kang, Z. The target gene of tae-miR164, a novel NAC transcription factor from the NAM subfamily, negatively regulates resistance of wheat to stripe rust. Mol. Plant Pathol. 2014, 15, 284-296. [CrossRef]

143. Katiyar, A.; Smita, S.; Muthusamy, S.K.; Chinnusamy, V.; Pandey, D.M.; Bansal, K.C. Identification of novel drought-responsive microRNAs and trans-acting siRNAs from Sorghum bicolor (L.) Moench by high-throughput sequencing analysis. Front. Plant Sci. 2015, 6. [CrossRef]

144. López-Galiano, M.J.; Sentandreu, V.; Martínez-Ramírez, A.C.; Rausell, C.; Real, M.D.; Camañes, C.; Ruiz-Rivero, O.; Crespo-Salvador, O.; García-Robles, I. Identification of Stress Associated microRNAs in Solanum lycopersicum by High-Throughput Sequencing. Genes 2019, 10, 475. [CrossRef] [PubMed]

145. Samad, A.F.A.; Sajad, M.; Nazaruddin, N.; Fauzi, I.A.; Murad, A.M.A.; Zainal, Z.; Ismail, I. MicroRNA and Transcription Factor: Key Players in Plant Regulatory Network. Frontiers 2017, 8, 1-18. [CrossRef] [PubMed]

146. Li, X.; Xing, X.; Xu, S.; Zhang, M.; Wang, Y.; Wu, H.; Sun, Z.; Huo, Z.; Chen, F.; Id, T.Y. Genome-wide identification and functional prediction of tobacco lncRNAs responsive to root-knot nematode stress. PLoS ONE 2018, 13, e0204506. [CrossRef] [PubMed] 
147. Li, G.; Zhang, H.; Shao, H.; Wang, G.; Zhang, Y.; Zhang, Y.; Zhang, Y.J.; Zhao, L.N.; Sheteiwy, M.S. ZmHsf05 a new heat shock transcription factor from Zea mays L. improves thermotolerance in Arabidopsis thaliana and rescues thermotolerance defects of the athsfa2 mutant. Plant Sci. 2019, 283, 375-384. [CrossRef] [PubMed]

148. Nagaraju, M.; Reddy, P.S.; Kumar, S.A.; Srivastava, R.K.; Kishor, P.B.K.; Rao, D.M. Genome-wide Scanning and Characterization of Sorghum bicolor L. Heat Shock Transcription Factors. Curr. Genomics 2015, 16, 279-291. [CrossRef] [PubMed]

149. Zhao, X.; Li, J.; Lian, B.; Gu, H.; Li, Y.; Qi, Y. Global identification of Arabidopsis lncRNAs reveals the regulation of MAF4 by a natural antisense RNA. Nat. Commun. 2018, 9, 1-12. [CrossRef] [PubMed]

150. Zhang, T.; Lv, W.; Zhang, H.; Ma, L.; Li, P.; Ge, L.; Li, G. Genome-wide analysis of the basic Helix- Loop-Helix (bHLH) transcription factor family in maize. BMC Plant Biol. 2018, 18, 1-14. [CrossRef]

151. Liu, W.; Tai, H.; Li, S.; Gao, W.; Zhao, M.; Xie, C.; Li, W.X. bHLH122 is important for drought and osmotic stress resistance in Arabidopsis and in the repression of ABA catabolism. N. Phytol. 2014, 201, 1192-1204. [CrossRef] [PubMed]

152. Perotti, F.; Ribone, A.; Chan, L. Plant Transcription Factors from the Homeodomain-Leucine Zipper Family I Role in Development and Stress Responses Subfamily HD-Zip I HD-Zip Family. Crit. Rev. 2017, 69, 280-289. [CrossRef]

153. Dixit, A.; Tomar, P.; Dhankher, O.P.; Vaine, E.; Hazen, S. A stress-Associated protein, AtSAP13, from Arabidopsis thaliana provides tolerance to multiple abiotic stresses. Plant Cell Environ. 2018, 1-15. [CrossRef]

154. United Nations. World Population Prospects: The 2012 Revision; United Nations: New York, NY, USA, 2013.

155. Bao, A.; Burritt, D.J.; Chen, H.; Zhou, X.; Cao, D.; Tran, L.S.P. The CRISPR/Cas9 system and its applications in crop genome editing. Crit. Rev. Biotechnol. 2019, 39, 321-336. [CrossRef] [PubMed]

(C) 2019 by the authors. Licensee MDPI, Basel, Switzerland. This article is an open access article distributed under the terms and conditions of the Creative Commons Attribution (CC BY) license (http://creativecommons.org/licenses/by/4.0/). 